\title{
Distinct mRNA Expression of the Highly Homologous Convertases PC5 and PACE4 in the Rat Brain and Pituitary
}

\author{
Weijia Dong, ${ }^{1}$ Mieczyslaw Marcinkiewicz, ${ }^{2}$ Didier Vieau, ${ }^{1}$ Michel Chrétien, ${ }^{2}$ Nabil G. Seidah, ${ }^{1}$ and Robert Day, ${ }^{1}$ \\ J. A. DeSève Laboratories of ${ }^{1}$ Biochemical and ${ }^{2}$ Molecular Neuroendocrinology, Clinical Research Institute of \\ Montreal, Montreal, Quebec, Canada H2W 1R7
}

Posttranslational endoproteolysis is essential for the production of biologically active peptides from inactive precursors. Six kexin/substilisin-like endoproteases have been characterized in mammalian species. To understand the complex physiological functions of each convertase within a cellular context it is necessary to comprehensively define its tissue distribution and cohabitation with other members of the family. Previous studies demonstrated the distinct distribution of PC1, PC2, and furin mRNAs in the pituitary and brain, suggesting a unique function for each enzyme. In the present study, the mRNA tissue distributions of the two most recent and homologous members, PC5 and PACE4, were analyzed in rat pituitary and brain using in situ hybridization histochemistry. In the pituitary, the anterior lobe exhibited moderate levels of PC5 and high levels of PACE4 mRNAs. The intermediate lobe showed low levels of PC5 expression, while PACE4 mRNA levels were undetectable. PACE4 transcripts were detected throughout cells of the neural lobe suggesting expression in pituicytes. In the brain, PC5 expression was more restricted than PACE4. PC5 mRNA was detected only in neuronal cells, whereas PACE4 mRNA was expressed in both neuronal and glial cells. In areas that are rich in neuropeptides such as cortex, hippocampus, and hypothalamus, mRNA levels of PC5 were high but PACE4 were low or undetectable. In regions, such as the amygdaloid body and thalamus, distinct but complementary distributions of PC5 and PACE4 mRNAs were observed. The medial habenular and cerebellar Purkinje cells expressed very high levels of PACE4 mRNA. The present data strongly suggest unique tissue-specific functions of PC5 and PACE4.

[Key words: enzymes, processing, cysteine-rich, in situ hybridization, Northern blot, localization]

The activation of newly synthesized pro-proteins often involves posttranslational processing via cleavage at distinct single or paired basic residues (Seidah and Chrétien, 1992). The discovery of kexin, an endoprotease that performs such functions in

\footnotetext{
May 23, 1994; revised Aug. 24, 1994; accepted Sept. 6, 1994.

We acknowledge the excellent technical assistance of Ms. Xue Wen Yuan. This work was supported by grants from the Medical Research Council (MRC) of Canada (PG11474 to M.C. and N.G.S. and MT11268 to R.D) and the J. A. DeSève Succession. R.D. is a scholar of the Fonds de la Recherche en Santé du Québec (FRSQ).

Correspondence should be addressed to Dr. Robert Day, J. A. DeSève Laboratory of Biochemical Neuroendocrinology, Clinical Research Institute of Montreal, 110 Pine Avenue West, Montreal, Quebec, Canada H2W 1R7.

Copyright (C 1995 Society for Neuroscience 0270-6474/95/151778-19\$05.00/0
}

yeast, lead to the identification of its mammalian homologs (Seidah, 1991). So far, six subtilisin/kexin-like mammalian prohormone convertases have been characterized and named furin (Roebroek et al., 1986; Van de Ven et al., 1990; or PACE, Barr et al., 1991), PC1 (Seidah et al., 1990, 1991b; also named PC3, Smeekens et al., 1991), PC2 (Seidah et al., 1990; Smeekens añd Steiner, 1990), PC4 (Nakayama et al., 1992; Seidah et al., 1992), PACE4 (Kiefer et al., 1991), and PC5 (Lusson et al., 1993; also named PC6, Nakagawa et al., 1993a). Previous studies showed the ubiquitous distribution of furin mRNA in the CNS encompassing both neuronal and glial cells, whereas PC1 and PC2 mRNAs are restricted to neurons and endocrine cells (Seidah et al., 1990, 1991; Day et al., 1992, 1993; Schäfer et al., 1993). PC4 is only expressed in germ cells (Nakayama et al., 1992. Seidah et al., 1992). These observed unique distribution patterns of each convertase suggested their involvement in the tissuespecific processing of precursor peptides.

Following signal peptidase cleavage of pre-pro-PC5, the resulting pro-PC5 is composed of an 881 amino acid protein which, similar to other PCs, contains a Lys-Arg pair of basic residues at the $\mathrm{N}$-terminal zymogen activation site. Upon $\mathrm{N}$-terminal cleavage, it was predicted that the 799 amino acid mature enzyme contains a C-terminal cysteine (Cys)-rich domain (Lusson et al., 1993). Northern analysis demonstrated a widespread tissue distribution of PC5, and preliminary in situ hybridization studies of rat CNS revealed a distribution of PC5 mRNA distinct from that of other PCs (Lusson et al., 1993). Cotransfection experiments have shown the calalytic function of PC5 in converting mutant mouse pro-renin-2 to renin-2 (Nakagawa et al., 1993a).

Northern analysis revealed a broad pattern of tissue expression of PACE4 (Kiefer et al., 1991), suggesting a wide but possibly distinct spectrum of action (Rehemtulla et al., 1993; Wasley et al. 1993). PACE4 was also demonstrated to have intracellular processing activity by cleaving pro-von Willebrand factor (Creemers et al., 1993; Rehemtulla et al., 1993). The catalytic domain of PACE4 exhibits $70 \%$ identity to that of PC5. Furthermore, both the size of the Cys-rich domain and the relative positions of the Cys residues are conserved in PC5 and PACE4, suggesting their similar intracellular localization and function (Lusson et al., 1993).

In view of this high degree of structural homology between PC5 and PACE4, it was, therefore, of interest to examine the expression of these two convertases in the pituitary and brain. The data demonstrates distinct cellular expression patterns of PC5 and PACE4 mRNA in these tissues, suggesting cell-specific functions. The comparison of the present results with our pre- 


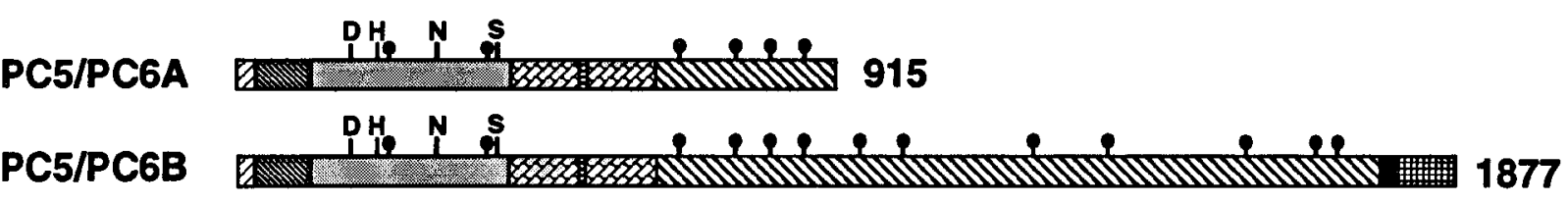

PACE4A

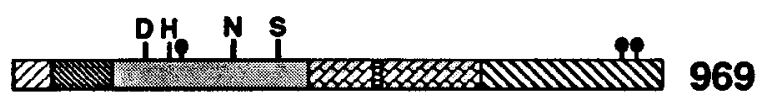

PACE4B

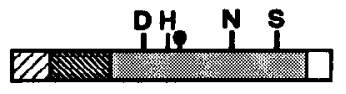

487

PACE4C

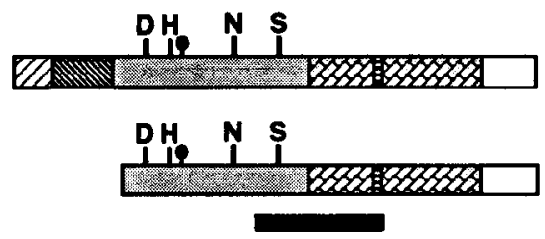

652

PACE4D

\section{7}

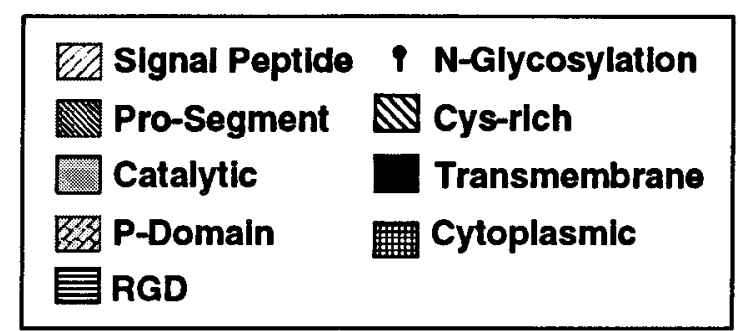

Figure 1. Schematic representation of PC5 and PACE4 protein structures and the various isoforms of each enzyme as previously described (Keifer et al., 1992; Nakagawa et al., 1993b; Tsuji et al., 1994). Note that PACE4A and PACE4B are also known as PACE4 and PACE4.1 (Keifer et al., 1991). The numbers at the end of each cDNA indicate the number of amino acids in each predicted protein. The black bars represent the two cRNA probes used in this study. In both cases, the probes selected will hybridize to each of the respective isoforms shown.

vious data (Day et al., 1992, 1993; Schäfer et al., 1993) allow a more detailed definition of the tissue distribution of the six convertases. These data suggest a complex cell-specific interplay between the convertases, emphasizing the need to define the nature of the convertase(s) involved in the processing of specific precursors and widening the debate on the potential complementary and/or redundant functions of the convertases.

\section{Materials and Methods}

Tissue preparation. Nine male Sprague-Dawley rats (200-250 gm) were used (six for brain study and three for pituitary study). Pituitaries and brains were rapidly removed and frozen in isopentane precooled to $-35^{\circ} \mathrm{C}$. Coronal, horizontal, and sagittal $(10-12 \mu \mathrm{m})$ sections were cut on a cryostat and thaw mounted on slides coated with polylysine and stored at $-80^{\circ} \mathrm{C}$ until further processing.

Probe synthesis. ${ }^{32} \mathrm{P}$-labeled (for Northern analysis) and ${ }^{35} \mathrm{~S}$-labeled (for in situ hybridization) cRNA probes were generated for PC5 and PACE4 from cDNA subclones in transcription vectors. The rat (r) PC5 cDNA used (837 nts, segment 1089-1925) has previously been described (Lusson et al., 1993). The rPACE4 cDNA (534 nts) was obtained by polymerase chain amplification of reverse transcribed total RNA extracted from rat heart tissues and corresponds to nts 1153-1687 of human PACE4 (Keifer et al., 1991). In Figure 1 are shown the positions of each CDNA fragment relative to the protcin structurc of PC5 and PACE4 and their isoforms. Specific activities of the ${ }^{35} \mathrm{~S}$-labeled cRNA probes were as follows: PC5, $5.4 \times 10^{5} \mathrm{Ci} / \mathrm{mmol}$; PACE4, 3.4 $\times 10^{5} \mathrm{Ci} / \mathrm{mmol}$. The probes were diluted in hybridization buffer $[75 \%$ formamide, $10 \%$ dextran sulfate, $3 \times \mathrm{SSC}, 50 \mathrm{~mm} \mathrm{NaPO}_{4}(\mathrm{pH} \mathrm{7.4)}, 1 \times$ Denhardt's $(0.02 \%$ each of Ficoll 400 , polyvinylpyrrolidone, BSA), 0.1 $\mathrm{mg} / \mathrm{ml}$ yeast RNA] to a final concentration of $33 \times 10^{3} \mathrm{dpm} / \mu \mathrm{l}$. Dithiothreitol was added to a final concentration of $20 \mathrm{~mm}$. The diluted probes were aliquoted and stored at $-80^{\circ} \mathrm{C}$.

Northern analysis. Total RNA was extracted from different regions of rat pituitaries and brains by a guanidine isothiocyanate extraction, immediately followed by lithium chloride precipitation (Day et al., 1992). For mRNA Northern analysis, poly $\left(\AA^{+}\right)$extraction was carried out as previously described (Day et al., 1992). The samples were transferred from the gel to a nylon filter, Nytran (Schleicher and Schuell, Keene, NH). After prehybridization at $62^{\circ} \mathrm{C}$ for $2 \mathrm{hr}$, hybridization was carried out for $16 \mathrm{hr}$ at $62^{\circ} \mathrm{C}$. The filters were washed in $0.1 \times \mathrm{SSC}$, $0.1 \% \mathrm{SDS}$, and $1 \mathrm{~mm}$ EDTA at $75^{\circ} \mathrm{C}$ for $3 \mathrm{hr}$, and exposed to x-ray film with intensifying screens at $-80^{\circ} \mathrm{C}$.
In situ hybridization histochemistry. The in situ hybridization protocols have been described elsewhere (Schäfer and Day, 1994). Briefly, frozen sections were fixed in $4 \%$ phosphate-buffered formaldehyde solution for $60 \mathrm{~min}$ at $4^{\circ} \mathrm{C}$ and then washed twice in $0.05 \mathrm{M} \mathrm{PBS}, \mathrm{pH} 7.4$, for $10 \mathrm{~min}$ each. The brain sections were treated with proteinase $\mathrm{K}(0.1$ $\mu \mathrm{g} / \mathrm{ml}, 5 \mathrm{~min}$ at $37^{\circ} \mathrm{C}$ ) and pituitary sections were treated with Triton $\mathrm{X}-100$ [0.4\% Triton X-100 in $0.05 \mathrm{M}$ PBS at room temperature (RT)], washed in DEPC water, and transferred to $0.1 \mathrm{M}$ triethanolamine, $\mathrm{pH}$ $8.0,5 \mathrm{~min}$ at RT. Slides were incuhated in $0.1 \mathrm{M}$ triethanolamine containing acetic anhydride $(0.25 \% \mathrm{v} / \mathrm{v})$ for $10 \mathrm{~min} \mathrm{RT}$, then rinsed in $2 \times$ saline-sodium citrate (SSC) and dehydrated in graded ethanol (50$100 \%)$. The cRN $\Lambda$ probes were applied $(30-50 \mu \mathrm{l}$ per slide) and hybridization was carried out at $55^{\circ} \mathrm{C}$ for $16 \mathrm{hr}$. The sections were then treated with RNase A $(40 \mu \mathrm{g} / \mathrm{ml})$ at $37^{\circ} \mathrm{C}$ for $45 \mathrm{~min}$, followed by a successive washes in $2 \times, 1 \times$, and $0.5 \times \mathrm{SSC}$ for $10 \mathrm{~min}$ each at RT and $0.1 \times \mathrm{SSC}$ for $45 \mathrm{~min}$ at $60^{\circ} \mathrm{C}$. Slides were dehydrated in graded ethanol and exposed to X-ray film (Kodak XAR-5) for 4-6 d. For cellular localization, slides were dipped in Kodak NTB2 nuclear emulsion (diluted $1: 1$ in $600 \mathrm{~mm}$ ammonium acetate), and stored at $4^{\circ} \mathrm{C}$ for $2-4$ weeks. Autoradiograms were developed in Kodak D19 for 2 min and fixed in $30 \%$ sodium thiosulfate for 4 min. All sections were counterstained with cresyl violet. It is noted that the use of cresyl violet as a counterstain, after the hybridization procedure, does not result in a typical Nissl staining. Since proteinase K and RNase A treatments are used, the Nissl staining (rough endoplasmic reticulum) disappears. However, weakly stained nuclei of neurons (large and pale blue stained) can be observed. On the other hand, the glial cell nuclei show strong purpleblue staining (smaller nuclei). As an additional control, adjacent untreated sections were used for cresyl violet slaining.

Controls. As negative control, radioactively labeled sense-strand probes of the same size and specific activity were applied instead of antisense-strand probes, and no positive labeling was encountered in the control experiments.

\section{Results}

Northern analysis

As shown in Figure 2, PC5 is expressed in the rat pituitary and various brain regions with high abundance in the cortex, hippocampus, and hypothalamus. For PACE4, the anterior lobe (AL) of pituitary, cerebellum, and spinal cord possess the highest mRNA levels. Although the antisense PC5 $\mathrm{cRN} \Lambda$ probe used in this study may pick up both PC5/PC6A and PC5/PC6B (Fig. 

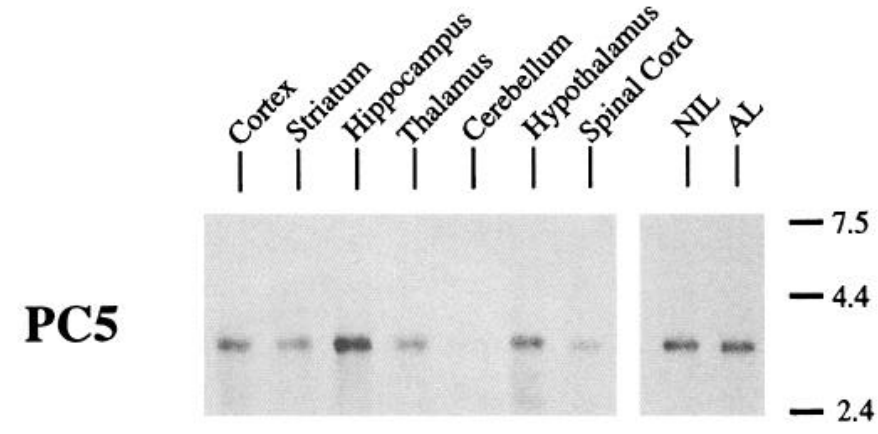

PACE4

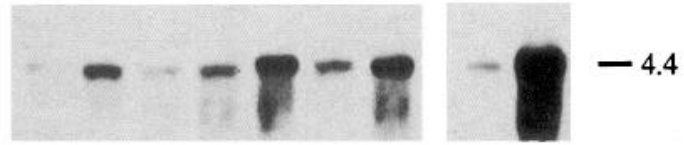

Figure 2. Northern blot analysis of PC5 and PACE4 distribution with poly $(\mathrm{A}+)$ RNA ( $5 \mu \mathrm{g}$ per lane) extracted from the rat pituitary and CNS. A major band is observed migrating at $3.8 \mathrm{~kb}$ for PC5 and at 4.4 $\mathrm{kb}$ for PACE4 in the rat pituitary and CNS.

1), our data shows that in the pituitary and brain the major form of PC5 mRNA is PC5/PC6A with molecular size of $3.8 \mathrm{~kb}$ (Fig. 2). Likewise, the PACE4 cRNA probe used should hybridize to each of the previously described PACE4 isoforms (Fig. 1). We could only observe the $4.4 \mathrm{~kb}$ form of PACE4 mRNA in poly $\mathrm{A}\left({ }^{+}\right)$RNA extracted from various brain regions and the pituitary.

\section{In situ hybridization}

Pituitary. The distribution of PC5 and PACE4 mRNAs was examined in the adult rat pituitary. Moderate to high levels of PC5 mRNA were observed in the cells of anterior lobe (Fig. 3A). Under higher magnification (Fig. $3 C$ ), variable cellular expression levels were observed showing a heterogeneous distribution. Strongly labeled cells were identified at the border zone adjacent to the intermediate lobe. Expression of PC5 mRNA was also found in some grouped cells in the intermediate lobe. In the neural lobe, PC5 mRNA was undetectable.

PACE4 mRNA levels were very high in the anterior lobe (Fig. $3 B$ ). This is evident by the strong signal observed in the anterior lobe and the short exposure time required ( $3 \mathrm{~d}$ for PACE4 as compared to 2 weeks for PC5). Interestingly, some anterior lobe cells with weaker expression levels were also observed (Fig. 3D, see arrows) indicating that not all anterior pituitary cells have high levels of PACE4 mRNA. It is not known if these cells represent a unique cell population or a heterogeneous group of cells. In the neural lobe, cells with moderate levels of PACE4 were observed (Fig. $3 F$ ). The observed signal was clearly associated with cellular structures (see arrows, $3 F$ ), suggesting the expression of PACE4 mRNA in pituicytes. In the intermediate lobe, PACE4 mRNA was undetectable. No specific labeling could be detected on sections hybridized with sense-strand probe to PC5 mRNA (Fig. 3E).

\section{Anatomic distribution of PC5 and PACE4 mRNAs in the rat brain}

Shown in Figures 4 and 5 are $x$-ray film autoradiograms of coronal sections of rat brain in rostral to caudal orientation that represent distinct distributions of PC5 and PACE4 mRNAs, respectively. It can already be seen that the gene expression of PC5 is more gray matter specific, while that of PACE4 is observed within both gray and white matter, suggesting a mixed neuronal/ glial character. The regional distributions of PC5 and PACE4 mRNAs are summarized in Table 1 and detailed in the sections below. The nomenclature and brain divisions are based on Paxinos (1985).

Rhinencephalon. In the olfactory bulb, weak to high levels of PC5 (Fig. 6B) and weak to moderate levels of PACE4 (Fig. 6C) gene expression were observed. The periglomerular cells expressed both PC5 and PACE4 mRNAs; the granular cells expressed low levels of PACE4, PC5 mRNA was undetectable, while the mitral cells (Mi) expressed high levels of PC5, whereas PACE4 mRNA was undetectable. In the external plexiform layer (EPl) some neurons showed low levels of PC5 mRNA; however, in the ventral extension of this layer a few neurons were strongly labeled with the PC5 probe. Some PACE4 expressing cells in this layer belong to the population of glial cells. In the anterior olfactory nucleus (AO), high levels of PC5 mRNA and weak levels of PACE4 mRNA were detected (Figs. $4 A, 5 A$ ). Moderate levels of PACE4 mRNA were also detected in neurons in the narrow white matter zone between ventral, lateral $\mathrm{AO}$, and lateral olfactory tract.

\section{Telencephalon}

Cortex. PC5 mRNA distribution was observed throughout the cerebral cortex from the frontal isocortex, parietal, and temporal cortex, and entorhinal cortex, namely in the layers III, V, and VI. In layer VI, strongly labeled cells were localized in the deepest stratum while cells in the upper portion were weakly labeled (Fig. $7 A$ ). From the view of development, the deepest stratum of layer VI originates from the former primordial plexiform layer (Künig et al., 1977; Raedler et al., 1980), indicating that cells in the same brain region but from different embryonic developing origins may express different levels of convertases. PACE4 mRNA levels were weak in the cortex (Fig. 5, Table 1). In contrast to PC5, the distribution pattern of PACE4 in the cortex was regionally different. In the frontal isocortex and parietal/temporal cortex, PACE4 was expressed in the layers V and VI, while in the entorhinal cortex, PACE4 was expressed in the layers II and III.

Hippocampal regions. In Figure $8 A$, high levels of PC5 mRNA were observed in the pyramidal cells of the subfield CA3 of Ammon's horn and scattered hilar cells, with low level in the subfield CA1 and dentate gyrus (DG). The expression of PC5 mRNA in the CA2 was weak in the caudal subfield (Fig. $4 F$ ), and undetectable in the rostral subfield with the exception of the transitional region between $\mathrm{CA} 3$ and $\mathrm{CA} 2$ where some cells were strongly labeled (Figs. $4 E, 8 A$ ). The restricted hippocampal distribution of PC5 gene expression suggests that PC5 could potentially be a good marker for the CA3 subfield of Ammon's horn where very few other markers are known. We could not detect any PACE4 mRNA in CA1, CA2, and CA3 of the hippocampal formation (Fig. $8 B$ ). However, in the DG, PACE4 mRNA showed heterogeneous distribution with undetectable levels in rostral division and weak levels in the caudal division (Figs. $5 E, F ; 8 B$ ). Therefore, it is interesting to note that in the hippocampal region each of the convertases, PC1, PC2, furin (Day et al., 1993; Schäfer et al., 1993), and PC5 (Lusson et al., 1993, and the present study) have highly distinct and sometimes overlapping expression patterns. Finally, very high levels of PC5 but not PACE4 mRNA were observed in the subiculum (S) (Fig. $7 B$ ), a region that expresses high levels of neurotensin/neuromedin N mRNA (Alexander et al., 1989).

Amygdala. A moderate to high levels of PC5 gene expression 

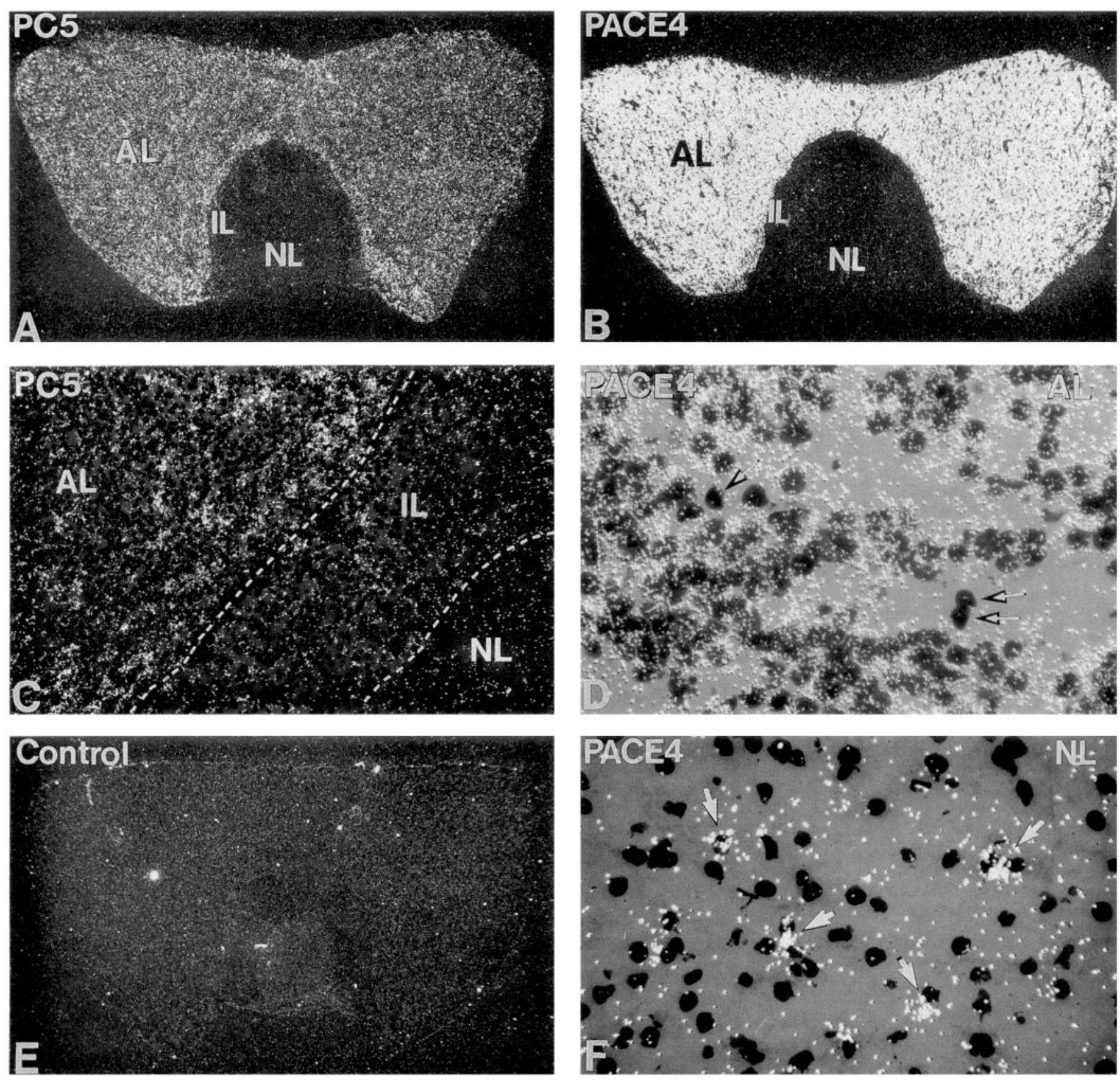

Figure 3. In situ hybridization distribution of PC5 and PACE4 mRNAs in emulsion-dipped rat pituitary sections. PC5 (A) and PACE4 (B) mRNAs distributions using antisense probes. $C$, High levels of PC5 mRNA were found in a region of anterior lobe adjacent to the intermediate lobe, low levels in the intermediate lobe, and no specific labeling in the neural lobe. $D$, Very high levels of PACE4 were observed in the anterior lobe. Cells with less labeling were observed (arrows). $E$, Control section using PC5 sense probe. $F$, Cells throughout the neural lobe were labeled with PACE4 mRNA antisense probe (arrows). Magnification: $A, B$, and $E$ ) $16 \times ; C, 119 \times ; D, 560 \times$; and $F, 425 \times$.

were present in most of the amygdaloid body with the exception of the central amygdaloid nucleus (Ce), where no PC5 mRNA was detected. PACE4 mRNA was expressed at low to moderate levels in this region. However, it is interesting to find that the highest levels of PACE4 mRNA in the amygdaloid body were present in the Ce. Figure $9, A$ and $B$, shows the complementary mRNA distribution of the two enzymes in this region with PC5 gene expression in the basolateral nucleus and PACE4 gene expression in the central nucleus.

Basal ganglia and other basal forebrain area. High levels of PC5 were observed in small to medium size neurons scattered throughout the globus pallidus. In the ventral pallidum, a few neurons were also strongly labeled. PACE4 mRNA was undetectable in both these regions. On the other hand, the accumbens nucleus and the region of the caudate-putamen $(\mathrm{CPu})$ showed low level PACE4 mRNA but not that of PC5. In the CPu, only glial cells were positive and in accumbens nucleus, only neurons at the border zone were positive for PACE4 gene transcripts. Low to moderate levels of PC5 gene transcripts were present in the intermediate and dorsal part of the lateral septum, and nucleus of the diagonal band, where the levels of PACE4 mRNA were generally very low. 

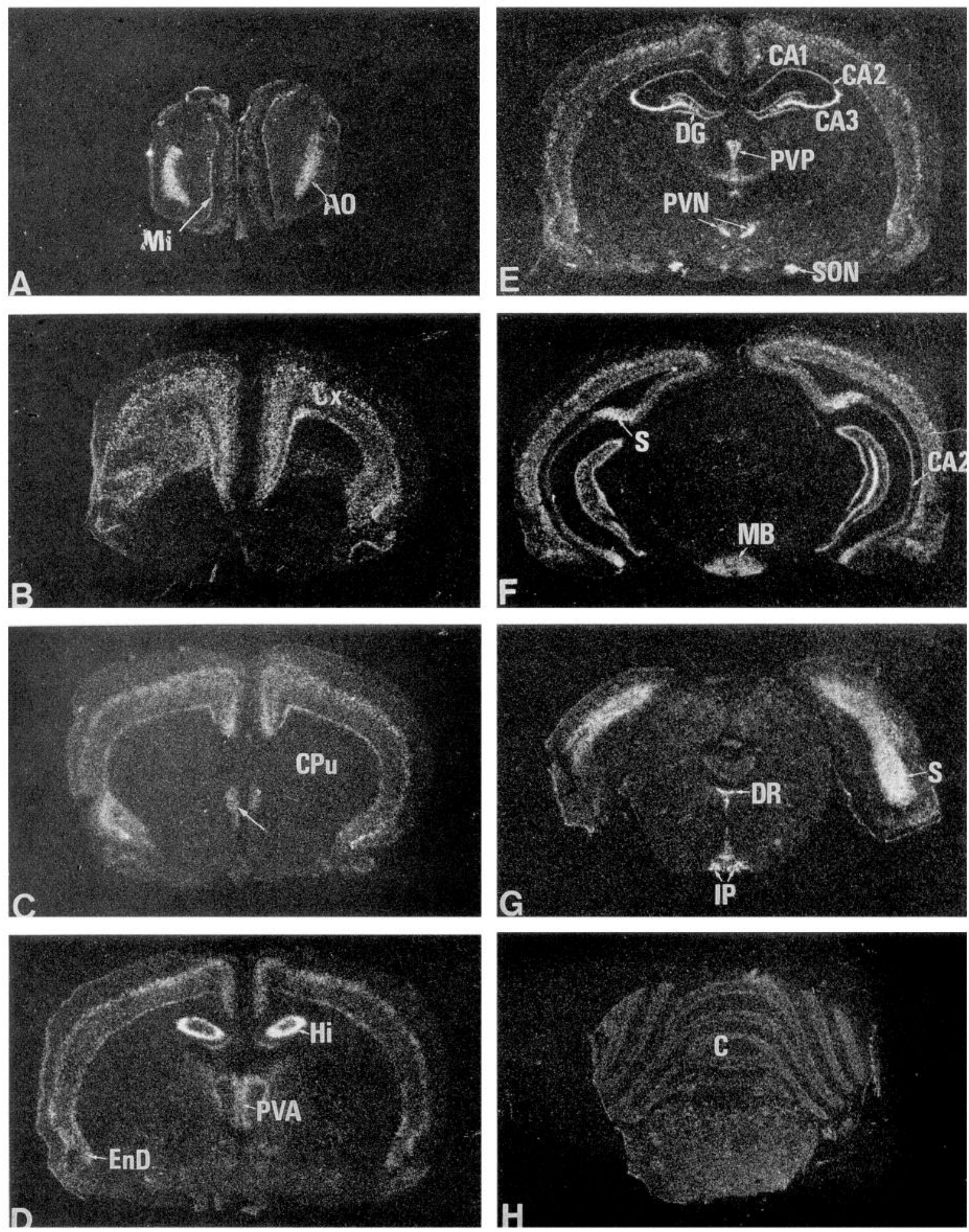

Figure 4. Autoradiograms of coronal sections in rostral to caudal direction ( $A-H$, respectively) showing the distribution of mRNA coding for processing enzyme PC5 in several brain regions. Note in the middle region of $C$, the piriform cortical tissue, which was positive for PC5, is still seen (arrow). Hybridization with ${ }^{35} \mathrm{~S}$-labeled cRNA probes revealed the gene transcripts as clusters of silver grains. The exposure time of the x-ray film was 144 hr. Magnifications are $4.5 \times$.

\section{Diencephalon}

Thalamus. In respect to its anatomical divisions, a complementary distribution of PC5 and PACE4 mRNAs was observed in the thalamus. PC5 mRNA was observed with variable levels of expression while low to moderate levels of PACE4 mRNA were also observed in the thalamus with the exception of ventrolateral (VL) and parafascicular nuclei where the levels of PACE4 mRNA are high. An example of the complementarity in the 

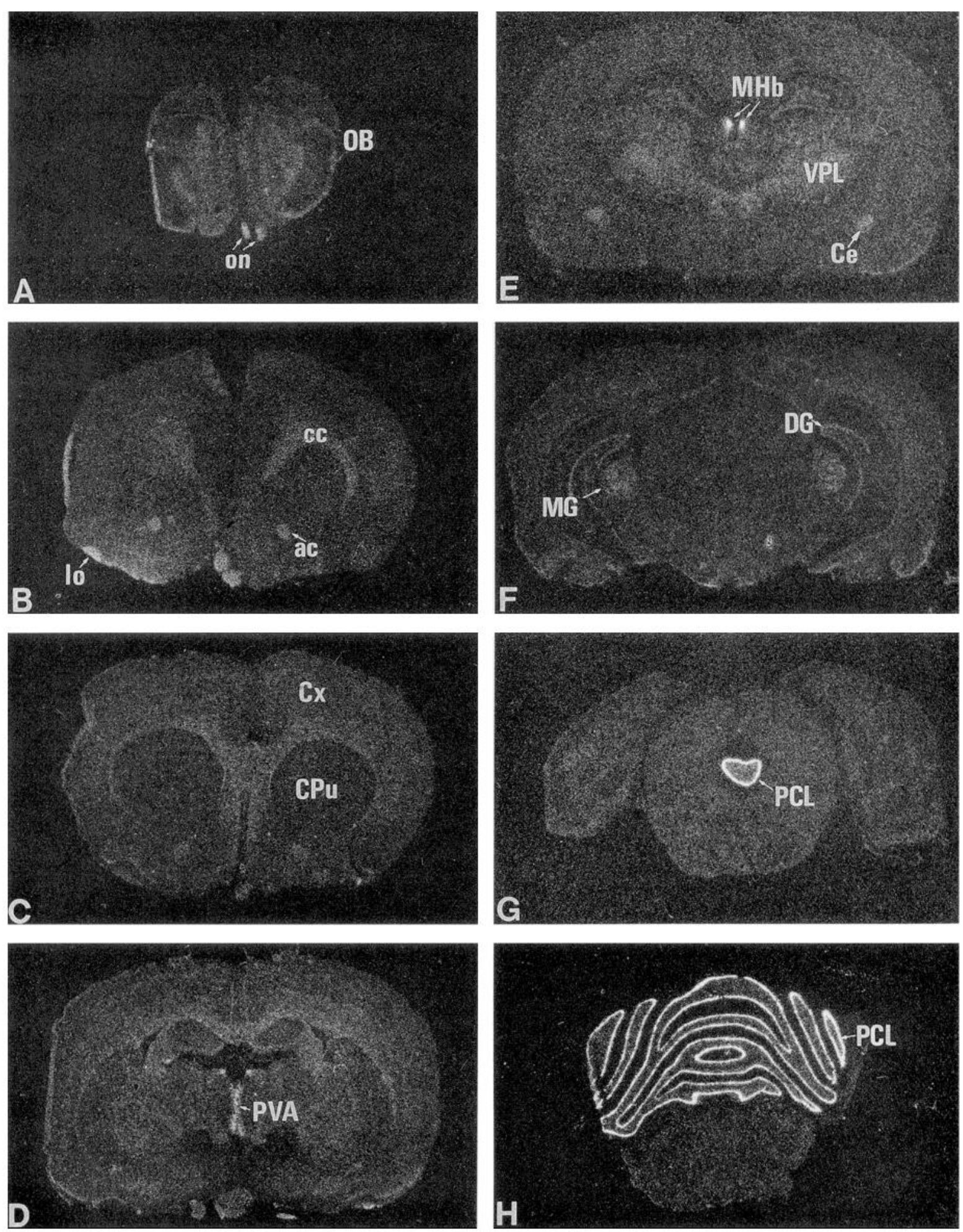

Figure 5. Autoradiograms of coronal sections in rostral to caudal direction ( $A-H$, respectively) showing the distribution of mRNA coding for processing enzyme PACE4 in several brain regions. Hybridization with ${ }^{35} \mathrm{~S}$-labeled cRNA probes revealed the gene transcripts as clusters of silver grains. The abbreviations are described in the Appendix. The exposure time of the $\mathrm{x}$-ray film was $144 \mathrm{hr}$. Magnifications are $4.5 \times$.

thalamus is shown in Figure 9, $C$ and $D$, where for PC5 mRNA high levels were observed in the intermediodorsal (IMD), centromedial (CM), and paracentral (PC) nuclei, while for PACE4, the expression of moderate to high mRNA levels was evident in the mediodorsal (MD) and VL. We also noted that in the posterior intralaminar nucleus, PC5 mRNA was detected only in the lateral extension.

Epithalamus. In the habenula, a region known to produce amidated neuropeptides such as the tachykinins (Burgunder and Young, 1989), PACE4 exhibited high levels of gene expression 


\begin{tabular}{|c|c|c|}
\hline Region & PC5 & PACE4 \\
\hline \multicolumn{3}{|l|}{ Pituitary } \\
\hline Neural lobe & 0 & $++^{*}$ \\
\hline Intermediate lobe & + & 0 \\
\hline Anterior lobe & +++ & +++++ \\
\hline \multicolumn{3}{|l|}{ Rhinencephalon } \\
\hline \multicolumn{3}{|l|}{ Olfactory bulb } \\
\hline Glomerular layer & ++ & ++ \\
\hline External plexiform layer & $++* \mathrm{~h}$ & ++ \\
\hline Mitral cells & ++++ & 0 \\
\hline Internal granular layer & 0 & $+*$ \\
\hline Ependymal and subependymal layer & 0 & $+*$ \\
\hline \multicolumn{3}{|l|}{ Anterior olfactory nuclei } \\
\hline Dorsal & ++++ & + \\
\hline Lateral & ++++ & +++ \\
\hline Medial & ++++ & ++ \\
\hline Ventral & ++++ & ++ \\
\hline Primary olfactory cortex & $+t+$ & +++ \\
\hline Lateral transitional zone & $++*$ & 0 \\
\hline \multicolumn{3}{|l|}{ Telencephalon } \\
\hline \multicolumn{3}{|l|}{ Frontal isocortex } \\
\hline Layer I & 0 & 0 \\
\hline Layer II & 0 & 0 \\
\hline Layer III & +++ & 0 \\
\hline Layer IV & 0 & 0 \\
\hline Layer V & ++++ & + \\
\hline \multicolumn{3}{|l|}{ Layer VI } \\
\hline Upper stratum & $++*$ & + \\
\hline Deepest stratum & ++++ & + \\
\hline \multicolumn{3}{|l|}{ Parietal and temporal cortex } \\
\hline Layer I & 0 & 0 \\
\hline Layer II & 0 & 0 \\
\hline Layer III & +++ & + \\
\hline Layer IV & 0 & 0 \\
\hline Layer V & ++++ & + \\
\hline \multicolumn{3}{|l|}{ Layer VI } \\
\hline Upper stratum & ++ & + \\
\hline Deepest stratum & ++++ & + \\
\hline \multicolumn{3}{|l|}{ Entorhinal cortex } \\
\hline Layer I & 0 & 0 \\
\hline Layer II & 0 & ++ \\
\hline Layer III & ++++ & ++ \\
\hline Layer IV & 0 & 0 \\
\hline Layer V & ++++ & 0 \\
\hline Layer VI & ++++ & 0 \\
\hline \multicolumn{3}{|l|}{ Limbic structures } \\
\hline \multicolumn{3}{|l|}{ Hippocampal formation } \\
\hline CAl & ++ & 0 \\
\hline \multicolumn{3}{|l|}{$\mathrm{CA} 2$} \\
\hline Rostral & 0 & 0 \\
\hline Caudal & ++ & 0 \\
\hline CA3 & ++++ & 0 \\
\hline Oriens layer of the hippocampal structure & +++ & 0 \\
\hline \multicolumn{3}{|l|}{ Dentate gyrus } \\
\hline Molecular layer & 0 & 0 \\
\hline Granular layer & + & 0 to $+^{h}$ \\
\hline Scattered hilar cells & ++++ & 0 \\
\hline Subiculum & ++++ & 0 \\
\hline
\end{tabular}


Table 1. Continued

Region

Amygdala

Anterior amygdaloid area

Anterior cortical nucleus

Posteromedial cortical nucleus

Medial nucleus

Basolateral nucleus

Central nucleus

Endopiriform nucleus

Dorsal

Ventral

Bed nucleus of the stria terminalis

Lateral

Medial

Basal ganglia

Accumbens nucleus

Caudate putamen

Globus pallidus

Ventral pallidum

Septum

Lateral septum, intermediate part

Lateral septum, dorsal part

Lateral septum, ventral part

Nucleus vertical limb diagonal band

Dorsal

Ventral

Nucleus horizontal limb diagonal band

Diencephalon

Thalamus

Anteroventral nucleus

Centromedial nucleus

Laterodorsal nucleus

Mediodorsal nucleus

Mediodorsal nucleus, lateral

Paracentral nucleus

Paraventricular thalamic nucleus

Anterior

Posterior

Intermediodorsal thalamic nucleus

Paratenial nucleus

Posterior intralaminar nucleus

Lateroposterior nucleus

Parafascicular nucleus

Rhomboid nucleus

Ventrolateral nucleus

Ventroposterior nucleus, lateral

Gelatinosus nucleus

Epithalamus

Habenula

Medial

Lateral

Anterior pretectal area

Posterior pretectal nuclcus

Hypothalamus

Median preoptic nucleus

Medial preoptic area

Lateral preoptic area

Medial preoptic nucleus

Suprachiasmatic nucleus

Retrochiasmatic area

Periventricular nucleus

Supraoptic nucleus

Posterior nucleus
PC5

PACE4

$++*$

$++$

$+++$

$+++^{*}$

$++$

$+$

$++$

$+$

$+$

$++*$

0

0

$+++*$

$+t+*$

$++$

$++$

0

$+$

$+t$

$++$

0

$+++$

$+$

0

$+$

$+++$

$++++$

$++++$

$+++$

0

$+++$

0

0

$++$

0

$++$

0

$+++*$

$++*$

$+++^{*}$

$++$

$++*$

$++$

$++*$

$++$

$++*$

$++t+$

$+$
$+++*$

$++$

0

$+$

0

$+++$

$+$

$+$

$+$

$+$

$+*$

$++*$

0

0

$+$

$+$

$+$

$+^{*}$
$+*$
+

$++$

$++$

$++$

0

$+$

+ to $++t^{h}$

0

$++$

0

$++$

$+++$

$+*$

$+++$

$++$

$+t$

$++++$

$+$

0

0

$+*$
+
++
++
++
++
++
+
+
+
+
+
+
+
+
+
+
+

$+++$

$+*$

$+$

$+t$

$+*$

0

0

0

0 
Table 1. Continued

Region

PC5

PACE4

Paraventricular hypothalamic nucleus

Anterior magnocellular

Anterior parvocellular

Medial parvocellular

Posterior magnocellular

Lateral parvocellular

Arcuate nucleus

Anterior

Posterior

Anterior area

Lateral area

Dorsal area

Perifornical nucleus

Tuber cinereum

Caudal magnocellular nucleus

Ventromedial nucleus

Dorsomedial nucleus, compact

Premammillary nucleus, dorsal

Medial mammillary nucleus

Lateral

Medial

Median

Posterior

Lateral mammillary nucleus

Postmammillary caudal magnocellular nucleus

Mammillary recess of the third ventricle

Mesencephalon

Third nerve occlumotor nucleus

Interstitial magnocellular nucleus of posterior commissure

Interstitial nucleus of the medial longitudinal fasciculus

Interstitial nucleus of Cajal

Dorsal lateral geniculate nucleus

Medial geniculate nucleus

Ventral lateral geniculate nucleus, parvocellular part

Zona incerta

Retrorubral field

$++++$

$+++\quad 0$

$+++^{*} \quad++*$

$++++\quad 0$

$++\quad+$

$0 /+$

$+++$

$++$

$+++$

$++*$

$++*$

$+*$

0

$+$

$+++$

$++$

$+++$

$++++$

$+*$

$++*$

0

$+++$

$+++$

$+$

$++$

$+++$

$+$

$++$

$+$

$+$

0

$++$

0

$++$

$++*$

0

0

$++$

$++$

$+++$

$+++*$

Pars compacta

Pars reticulata

Pas lateralis

Nucleus of Darkschewitsch

Ventral tegmental area

Central gray

Deep mesencephalic nucleus

Red nucleus

Dorsal raphé nucleus

Caudal linear raphé nucleus

Median raphé nucleus

Superior colliculus

Inferior colliculus

Interpeduncular nucleus

$+++*$

$++*$

$+++$

$+*$

$++*$

$+++*$

$+++$

$++++$

$++$

$+++$

$+++$

$++$

++ to ++++ h

Pons and medulla

Pontine nuclei, medioventral group

Raphé pontis nucleus

Laterodorsal tagmental nucleus

Locus coeruleus

$++++1$

$+++$

$+++$

$+++$

$++*$

$++*$

$+$

$+$

0

$+$

$++$

$+++$

$+++*$

Dorsal parabrachial nucleus

Ventral parabrachial nucleus

$+$

$++$

0

$++* *$

$++$

$++$

$++$

0

$++$

$+*$

$+*$

$+$

$++*$

$+*$

$+$

$+$

$+*$

$+$

+
+

$+$

$+$

0

0

$+++t^{h}$

$+$

$+$

0

$++$

$++$ 


\section{Table 1. Continued}

\begin{tabular}{|c|c|c|}
\hline Region & PC5 & PACE4 \\
\hline Kölliker-Fuse nucleus & $++*$ & ++ \\
\hline Ventral tegmental nucleus & 0 & ++ \\
\hline Dorsal tegmental nucleus & 0 & ++ \\
\hline Mesencephalic tract trigeminal nerve nucleus & $+++*$ & $++++*$ \\
\hline Dorsal cochlear nucleus & $++^{h}$ & ++ \\
\hline \multicolumn{3}{|l|}{ Pontine reticular nucleus } \\
\hline Oral & $++*$ & ++ \\
\hline Caudal & $++++*$ & $+*$ \\
\hline Lateral vestibular nucleus & 0 & ++ \\
\hline Medial nucleus of the trapezoid body & 0 & +++ \\
\hline Nucleus raphé pallidus & 0 & +++ \\
\hline Paragigantocellular reticular nucleus & $+++\mathrm{h}$ & +++ \\
\hline Superior olive nucleus & 0 & ++ \\
\hline Inferior olive nucleus & ++++ & 0 \\
\hline Facial nucleus & ++++ & 0 \\
\hline Giganticular reticular nucleus & $+++h$ & $++h$ \\
\hline Parvocellular reticular nucleus & 0 & ++ \\
\hline Nucleus tractus solitarius & +++ & 0 \\
\hline Prepositus hypoglossal nucleus & $+++*$ & 0 \\
\hline Nucleus of the spinal tract of the trigeminal nerve, oral part & +++ & 0 \\
\hline \multicolumn{3}{|l|}{ Cerebellum } \\
\hline \multicolumn{3}{|l|}{ Cortex } \\
\hline Molecular layer & 0 & + \\
\hline Purkinje cell layer & 0 & ++++ \\
\hline Granular layer & + & + \\
\hline \multicolumn{3}{|l|}{ Deep nuclei } \\
\hline Lateral cerebellar nucleus & +++ & 0 \\
\hline Interpositus cerebellar nucleus & +++ & 0 \\
\hline \multicolumn{3}{|l|}{ White matter } \\
\hline Optic nerve & 0 & ++ \\
\hline Optic chiasm & 0 & ++ \\
\hline Lateral olfactory tract & 0 & ++ \\
\hline Anterior commissure & 0 & + \\
\hline Posterior commissure & 0 & ++ \\
\hline Corpus callosum & 0 & ++ \\
\hline Forceps minor corpus callosum & 0 & + \\
\hline Genu of the corpus callosum & 0 & + \\
\hline White matter of the cerebellar folia & 0 & ++ \\
\hline \multicolumn{3}{|l|}{ Circumventricular organs } \\
\hline Subfornical organ & +++ & + \\
\hline Choroid plexus & 0 & 0 \\
\hline Ependyma of the third ventricle & 0 & $+++h$ \\
\hline Subcommissural organ, hypendyma & 0 & $+*$ \\
\hline Pineal gland, pia matter & +++ & 0 \\
\hline Area postrema & + & 0 \\
\hline \multicolumn{3}{|l|}{ Brain associated structures } \\
\hline Virchow's structures & + & 0 \\
\hline Arachnoid & ++ & 0 \\
\hline
\end{tabular}

* Scattered cells are observed.

${ }^{n}$ Hetereogeneous distribution in a nucleus.

while PC5 mRNA was undetectable (see Fig. 13A). The distribution of PACE4 mRNA was predominant at the upper portion of the medial habenula (MHb). This is one of the two areas where PACE4 mRNA can be sharply illustrated using $x$-ray film (Fig. $5 E$ ) in the present study; the other area is the Purkinje cell layer of the cerebellum (Fig. $5 H$ ). Additionally, the lower portion of the $\mathrm{MHb}$ and the lateral habenula show weak labeling for PACE4 mRNA. In the anterior pretectal area and posterior pretectal nucleus, some neurons express low to moderate levels of PC5 but not PACE4.

Hypothalamus. The hypothalamus, a brain region characterized by high concentrations of neuropeptides, expresses both PC5 and PACE4 genes with prominent regional specificity. For example, high levels of PC5 mRNA were noted in the magno- 

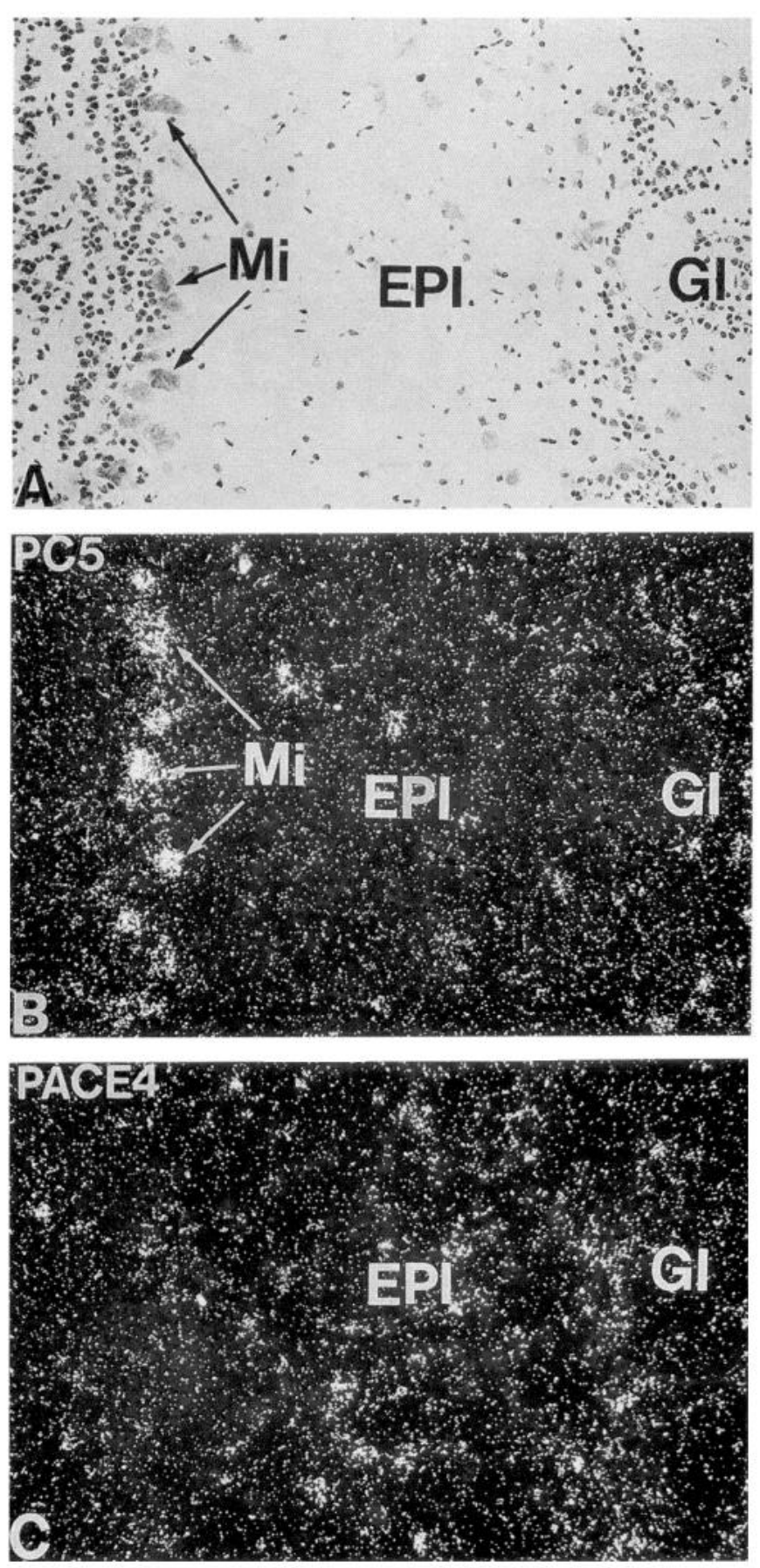

Figure 6. In situ hybridization distribution of PC5 and PACE4 mRNAs in the olfactory system. $A$, For identification of cellular structures an adjacent section was counterstained with cresyl violet. $B$, The mitral cells (Mi) express high levels of PC5. Scattered cells were labeled in the external plexiform $(E P l)$ and glomerular layers $(G l)$. $C$, PACE4 mRNA was undetectable in the Mi. In the EPI and Gl, more cells express PACE4 than PC5. Magnifications are $130 \times$.

cellular neurons of the paraventricular nucleus (PVN) and supraoptic nucleus (SON) (Fig. 10), where multiple neuropeptides are well identified (Bondy et al., 1989). These two nuclei also express other convertases including PC1, PC2, and furin (Schäfer et al., 1993). PACE4 mRNA was undetected in these magnocellular neurons. Within the parvocellular neurons of the PVN, different levels of PC5 and PACE4 mRNA expression
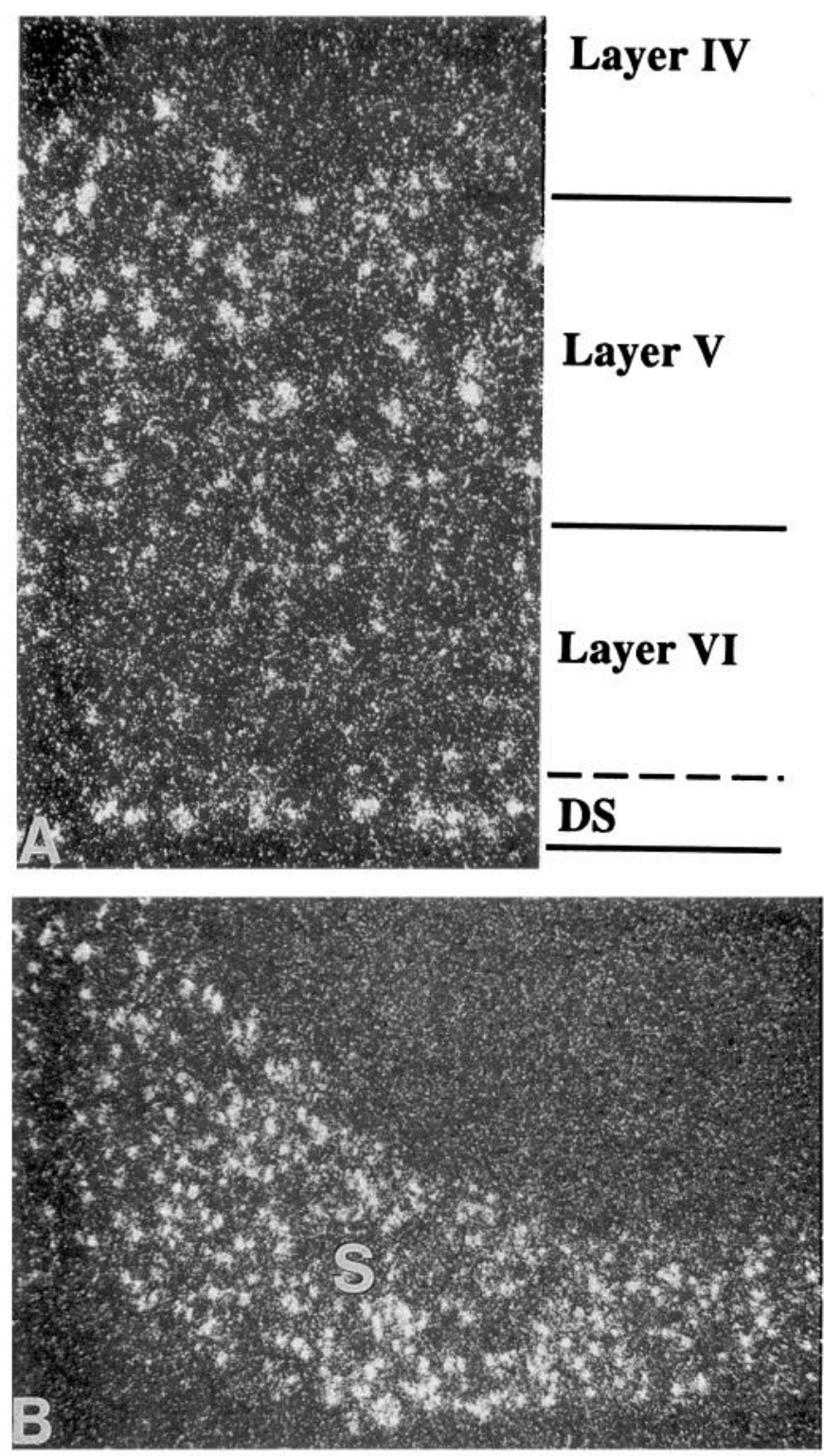

Figure 7. Distribution of PC5 mRNA $(A)$ in layer V and VI of the cortex, and $(B)$ in the subiculum $(S)$. High levels of PC5 mRNA are seen in layer $\mathrm{V}$ and deepest stratum $(D S)$ of layer VI. Magnifications are $(A) 100 \times$ and $(B) 65 \times$.

were seen. For PC5 mRNA, cells of the anterior parvocellular region exhibited high levels, a few cells in medial parvocellular region exhibit moderate levels, and cells in the lateral parvocellular region exhibited low levels. For PACE4 mRNA, some cells in medial parvocellular region exhibit moderate levels while cells in the lateral parvocellular region exhibit low levels.

High levels of PACE4 mRNA were observed in neurons of the arcuate nucleus (Arc) subregion near the basal hypothalamus (Fig. 11E), an area known to express high levels of proopiomelanocortin (POMC). PC5 mRNA was expressed at moderate levels in the posterior portion of this nucleus (Fig. 11C).

In the mammillary body (MB), low to medium levels of PC5 transcripts were identified. High levels of PACE4 mRNA were detected in postmammillary caudal magnocellular nucleus. In mammillary recess of the third ventricle, a few scattered cells were strongly labeled with PACE4 mRNA probe. However, in 

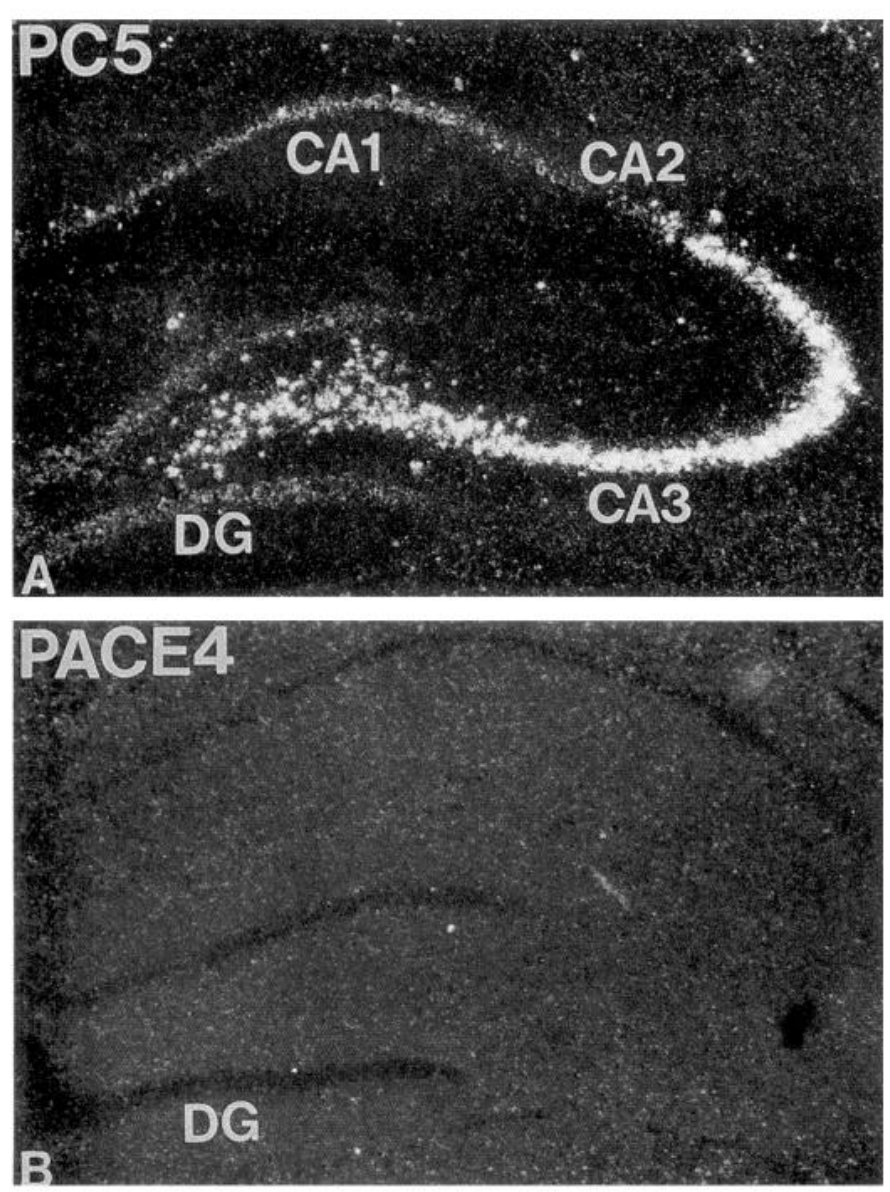

Figure 8. Localization of $(A)$ PC5 and $(B)$ PACE4 mRNAs in the hippocampal formation. High level of PC5 gene expression was observed in granular layer of CA3 and scattered hilar cells. CA1 and dentate $(D G)$ are weakly labeled. Although some cells in the transitional zone between subfield CA2 and CA 3 were labeled, we still considered $\mathrm{CA} 2$ as negative for PC5, because in the major portion of this small region PC5 mRNA was undetectable and the few labeled cells may belong to CA3. PACE4 mRNA is shown for comparison. Magnifications are $85 \times$.

the other regions of the MB, PACE4 mRNA levels were low or undetectable. In summary, PC5 gene expression is stronger and more widely distributed than PACE4 in the hypothalamic region.

\section{Mesencephalon}

In mesencephalon, PC5 and PACE4 mRNAs were widely distributed. Several regions expressing high levels of PC5 mRNA were identified, including retrorubral field, red nucleus, dorsal raphé nucleus (DR), and subregions of the interpeduncular nucleus (IP), where the levels of PACE4 mRNA were very low or undetectable. In the substantia nigra, a neuropeptide-rich region, moderate levels of PC5 mRNA and low levels of PACE4 mRNA were observed in cells scattered throughout this region. The pars compacta of this region, where high levels of PC1, CPE, and PAM mRNA were found (Schäfer et al., 1993), also expressed PC5 mRNA in dispersed neurons. In general, higher levels of PC5 mRNA than PACE4 mRNA were observed in most of the regions of the mesencephalon with notable exceptions such as interstitial magnocellular nucleus of posterior commissure, the dorsal lateral and medial geniculate nuclei (MG) which express low to moderate levels of PACE4 mRNA but no PC5 mRNA.

\section{Pons and medulla}

Although some nuclei in the pontine region express both PC5 and PACE4 genes, many areas of this region express only one of these two convertases. For example, the solitary tract nucleus (NTS) (Fig. 11B), a region expressing POMC (Schäfer et al., 1990a), and the inferior olivary nucleus, a region which expresses high levels of IGF-I (Torres-Aleman et al., 1991) exhibit high levels of PC5 mRNA (Fig. 11D,F), whereas, no PACE4 mRNA can be detected in these regions. The nucleus of raphé pallidus and trapezoid body medial nucleus express moderate levels of PACE4 but not PC5 mRNA. In the medioventral group of pontine nuclei, both PC5 and PACE4 mRNAs were expressed; however, because of the regional variation of the distribution, there are no areas exhibiting both enzymes in this group of nuclei. PACE4 mRNA was observed in some neurons scattered around the dorsal margin of the VIIth nerve and this distribution pattern outlined the central region of the nerve. The magnocellular neurons of mesencephalic tract trigeminal nerve nucleus expressed high levels of PACE4 and moderate levels of PC5 mRNAs.

\section{Cerebellum}

Cortex. PC5 mRNA was undetectable in the cerebellar cortex (Fig. 12A). Very high expression levels of PACE4 mRNA were observed in the Purkinje cell layer (PCL) (Fig. 12C,D), and low levels were noted in some scattered cells in the molecular and granular layers (GL) (Fig. 12D).

Deep nuclei. While PACE4 expression was not observed in the cerebellar deep nuclei (Fig. 12C), high levels of PC5 mRNA were present in the neurons of two deep nuclei, namely the lateral (Lat) and interpositus (Int) cerebellar nuclei (Fig. 12A). It can be seen at higher magnification of the Lat that the labeling corresponds to neurons (Fig. 12B).

White matter. No detectable PC5 gene expression was found in the white matter of the rat brain, but low levels of PACE4 mRNA was identified in glial cells of some regions of the white matter including the optic nerve (on) (Fig. 13E,F), optic chiasm (ox), lateral olfactory tract, corpus callosum (cc), anterior commissure (ac), and white matter (wm) of cerebellum.

\section{Circumventricular organs}

The circumventricular organs expressed distinct levels of PC5 or PACE4 mRNA. Regions where PC5 gene was expressed include subfornical organ and area postrema. PACE4 mRNA was detected in a few ependymal cells in the region of the subcommissural organ. At the Monroe region of the third ventricle (3V), ependymal cells were moderately PACE4 positive (Fig. 13C,D).

\section{Brain-associated structures}

Low levels of PC5 mRNA were sometimes observed in Virkchof's structure and the arachnoid, where PACE4 mRNA was undetectable. In general, our systematic survey of the cerebral tissue allows us to conclude that PC5 gene expression is consistently evident in specific subsets of neuronal populations, with little if any expression in glial cells. Interestingly, PACE4 mRNA expression was observed not only in neuronal cell subpopulations within the gray matter, but also in glial cell subsets, heterogeneously distributed throughout the wm. The identification of neuronal and non-neuronal cells was based on the cresyl violet staining, showing neuronal nuclei as larger and paler, and glial nuclei as smaller and dense. 

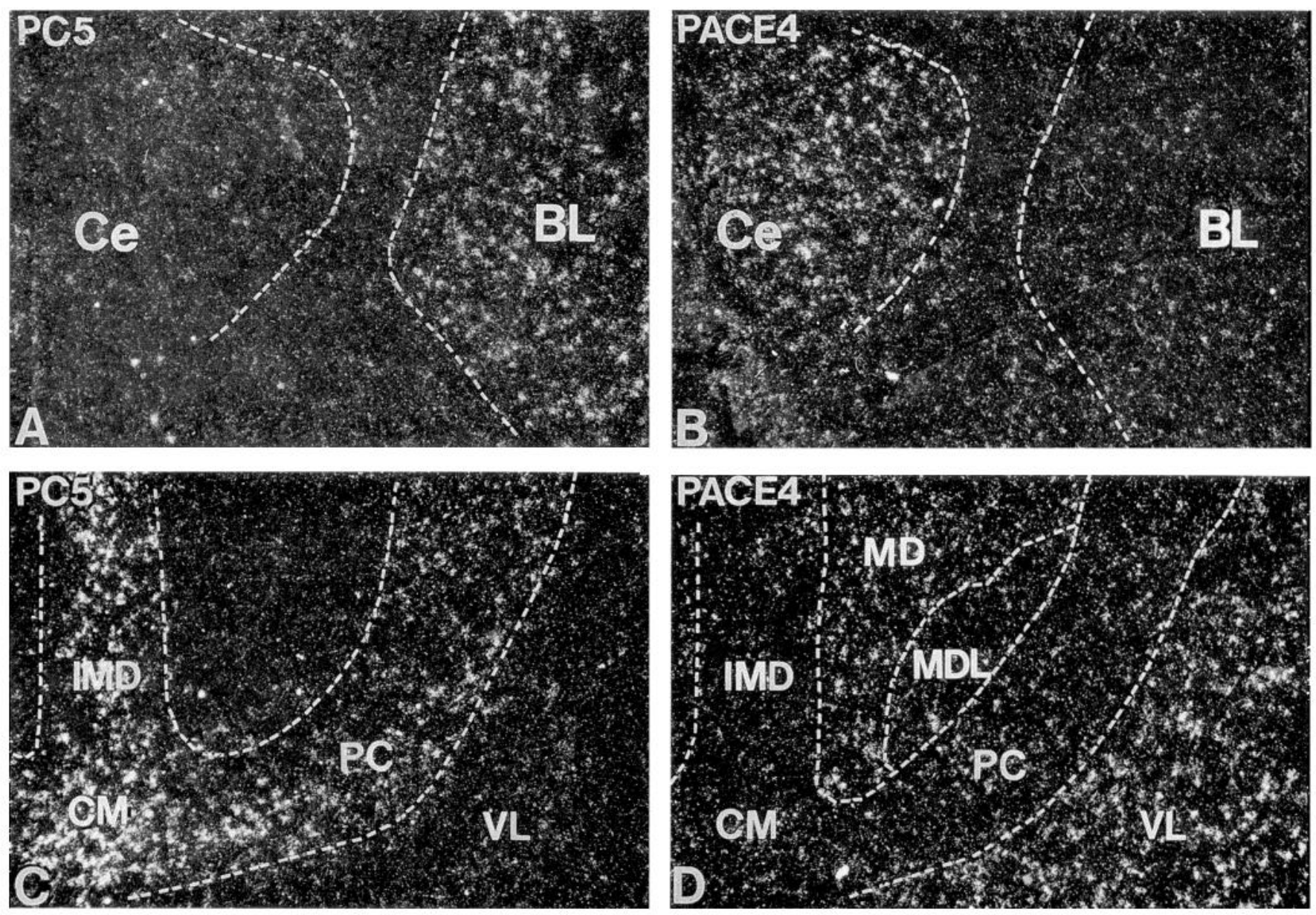

Figure 9. Complementary distribution of $(A$ and $C)$ PC5 and $(B$ and $D)$ PACE4 mRNAs in the $(A$ and $B)$ amygdaloid body and $(C$ and $D)$ thalamus. In the amygdaloid body, many regions express PC5 gene with moderate to high level, such as basolateral nucleus $(B L)$ where PACE4 mRNA is very low, while a high level of PACE4 mRNA is observed in the central nucleus $(\mathrm{Ce})$ where PC5 mRNA is undetectable. In the thalamic region, PC5 mRNA is dominant in the intermediodorsal $(I M D)$, central medial $(C M)$, and paracentral nuclei $(P C)$ and PACE4 mRNA is predominant in central mediodorsal $(M D)$ and ventrolateral nuclei $(V L)$. Magnifications are $55 \times$.

\section{Discussion}

In previous studies, we demonstrated the heterogeneous mRNA distribution of PC1, PC2, and furin, in the rat pituitary (Day et al., 1992) and CNS (Day et al., 1993, Schäfer et al., 1993). The present study examined the pituitary and CNS distribution of two recently characterized and highly homologous members of the family, namely PC5 and PACE4. From the detailed mapping we conclude that PC5 and PACE4 exhibit distinct expression patterns that also differ from those of other convertases. Although PC5 and PACE4 possess similar structure, it is possible that the cleavage specificity of the two convertases is not the same and, hence, the result would be divergent tissue-specific functions. In support of this hypothesis, preliminary results from our laboratory suggest that PC5 and PACE4 do not have similar pro-proteins cleavage preferences (S. Benjannet and N. G. Seidah, unpublished observations).

In situ hybridization examination of the pituitary demonstrates medium to high levels of PC5 mRNA within the anterior lobe with the highest levels in a region known to be rich in gonadotrophs and lactotrophs. The anterior lobe expressed very high levels of PACE4 mRNA. It is clear that more than one anterior pituitary cell type expresses these convertases. PACE4 mRNA was also detected in cells of the neural lobe. Pituicytes, which are the dominant cell type in the neural lobe, have structural and functional similarity to astroglia (Salm et al., 1982). Although neither PC5 (this study), nor PC1 and PC2 (Day et al., 1992) transcripts were detected in the pituitary neural lobe, we did observe furin expression (Day et al., 1992). Therefore, both PACE4 and furin could have precursor processing functions in the pituicytes. Various proteins expressed in pituicytes could be putative substrates for PACE4 or furin, including pro-enkephalin which is highly expressed in these glial-like cells (Schäfer et al., 1990b). However, if PACE4 and/or furin are involved in the cleavage of this precursor, they may only do so in a limited fashion since primarily intermediate size products and no small Met-enkephalin were detected in glial cells (Batter et al., 1991). This hypothesis is supported by studies demonstrating the limited processing of pro-enkephalin by furin (Breslin et al., 1993). The cleavage of pro-enkephalin by PACE4 has not been tested but will be the object of future studies. Such limited proteolysis is all the more important since intermediate pro-enkephalin molecules have been implicated in trophic functions, neuroimmune interactions, or trauma-induced CNS injury or stress (Low et al., 1992; Negro et al., 1992).

In the CNS, PC5 gene expression was unique and more restricted than that of PACE4. For example, while PC5 expression 

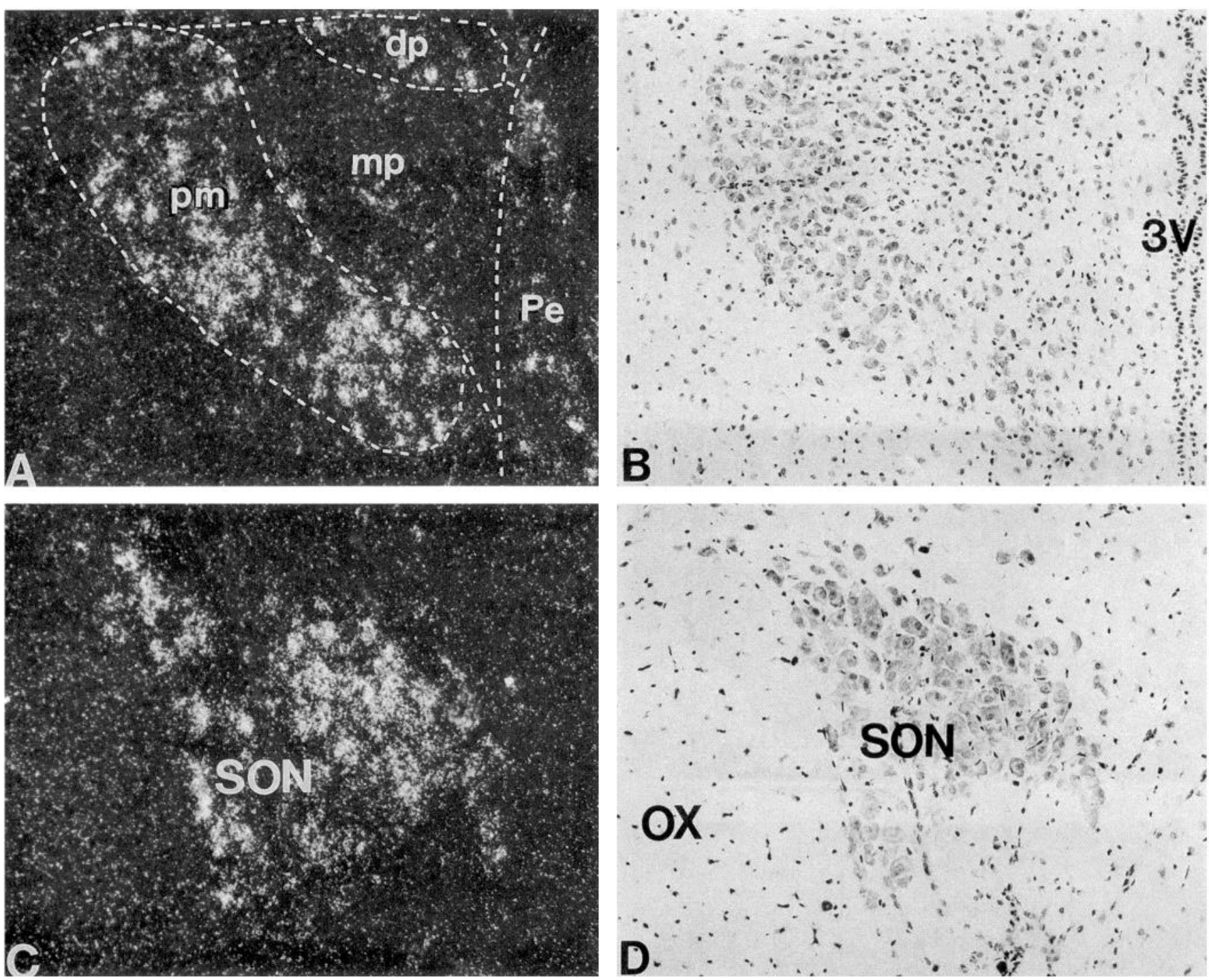

Figure 10. Distribution of PC5 mRNA in the $(A)$ paraventricular hypothalamus nuclei and $(C)$ supraoptic nucleus. Note that the majority of neurons in the posterior magnocellular $(\mathrm{pm})$ region expressed high levels, and a few scattered neurons in the medial parvocellular $(\mathrm{mp})$ region expressed low to moderate levels of PC $5(A)$. In the supraoptic nucleus $(S O N)$, many magnocellular neurons expressed high levels of PC5. Cresyl violet stained adjacent sections were obtained for cell identification $(B)$ paraventricular nucleus, and $(D)$ supraoptic nucleus. Magnifications are $(A$ and $B) 100 \times$; and $(C$ and $D) 130 \times$.

could only be detected in neurons, PACE4 mRNA is found in both neuronal and non-neuronal cells. Northern analysis of PC5 mRNA demonstrated that the cRNA probe used in the present study recognized at least three isoforms $(3.8,6.5$, and $7.5 \mathrm{~kb})$ (Lusson et al., 1993). The $7.5 \mathrm{~kb}$ isoform represents a C-terminally extended PC5 protein which includes a Cys-rich motif repeated 22 times (Nakagawa et al., 1993b), as compared to the 5 times repeat found in PC5 (Lusson et al., 1993). Our result indicates that these Cys-rich extended forms represent minor species in the CNS, while the in situ hybridization data mainly reflect the tissue distribution of the $3.8 \mathrm{~kb}$-sized mRNA since it represents the predominant form of PC5 in brain.

PACE4 expression was very high in some restricted CNS areas, but many other regions expressed low to moderate levels of PACE4. A major concern was to distinguish low levels from background labeling. When we compared signals obtained with the antisense PACE4 cRNA probe with those of the control sections treated with PACE4 sense-strand probe, it was con- cluded that low levels of PACE4 mRNA are expressed in a widespread manner. Northern blot analysis of PACE4 mRNA performed under stringent hybridization conditions confirmed these results and demonstrated that in various dissected brain regions the mRNA coding for PACE4 migrated with the expected size of $4.4 \mathrm{~kb}$. We, therefore, suggest that within the CNS, aside from certain hot spots, PACE4 mRNA is expressed in a widespread manner at a low cellular level. Similar contrasting patterns of expression were also shown for furin in the CNS, with high expression in the subsets of ependymal cells and the choroid plexus and much lower levels elsewhere (Day et al., 1993). However, different from furin, which is clearly expressed in a ubiquitous manner in the CNS (Day et al., 1993), PACE4 mRNA could not be detected in all cells, even at low levels. It is interesting to note that of all the convertases only furin and PACE4 are detected in glial and gliallike cells in the CNS. These two enzymes are found in the same chromosome (Roebroek et al., 1986; Keifer et al., 1991) 

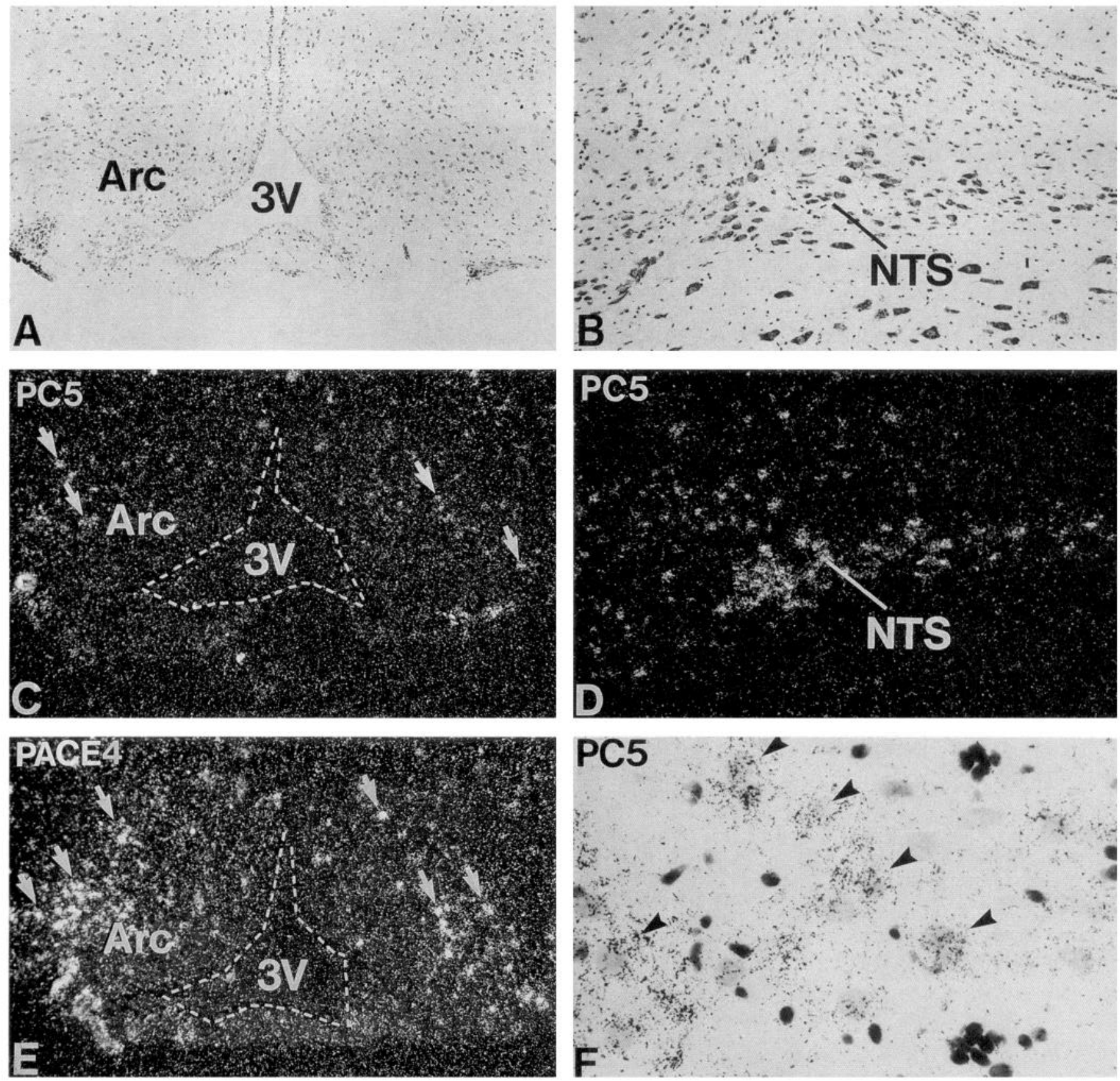

Figure 11. Distribution patterns of $(C, D$, and $F)$ PC5 and $(E)$ PACE4 mRNAs in the $(A, C$, and $E)$ arcuate $(A r c)$ hypothalamus nucleus and $(B$, $D, F)$ the nucleus of the solitary tract $(N T S)$; two POMC-producing nuclei in the brain. For identification of cellular structures, adjacent sections were counterstained with cresyl violet $(A)$ arcuate nucleus and $(B)$ nucleus of the solitary tract (sagittal section). Note in $C$ the scattered cells in the Arc express moderate levels of PC5, while in $E$, many more cells in this nucleus express high levels of PACE4. D, High levels of PC5 mRNA were detected in the NTS. $F$, With higher magnification and bright-field image, the labeling could be observed within neuronal cells. Magnification: $A, C$, and $E, 65 \times ; B$ and $D, 90 \times$; and $F, 520 \times$.

and may have evolved more recently than the other convertases.

The expression of each convertase in specific brain regions raises interesting questions as to their physiological roles, the nature of their putative substrates, and whether these proteinases have overlapping and/or distinct functions. For example, the hypothalamic PVN is rich in convertase expression and synthesizes many neuropeptides (Lightman, 1988). The present data demonstrated that the expression of PC5 is predominant in magnocellular neurons in the anterior magnocellular (am) and posterior magnocellular (pm) divisions of the PVN. The distribution pattern of PC5 positive cells is similar to that of the oxytocin cells (Sawchenko and Swanson, 1982). We have previously shown that PC1 and PC2 are also expressed in the PVN (Schäfer et al., 1993). In this nucleus, $\mathrm{PCl}$ is abundantly expressed in magnocellular cells in the pmPVN but also in scattered magnocellular cells in the medial parvocellular (mp) division of PVN. PC2 is more abundantly expressed in the parvocellular division of the PVN, but significant expression levels were also observed in the magnocellular cells. Taken together, these data suggest that va- 

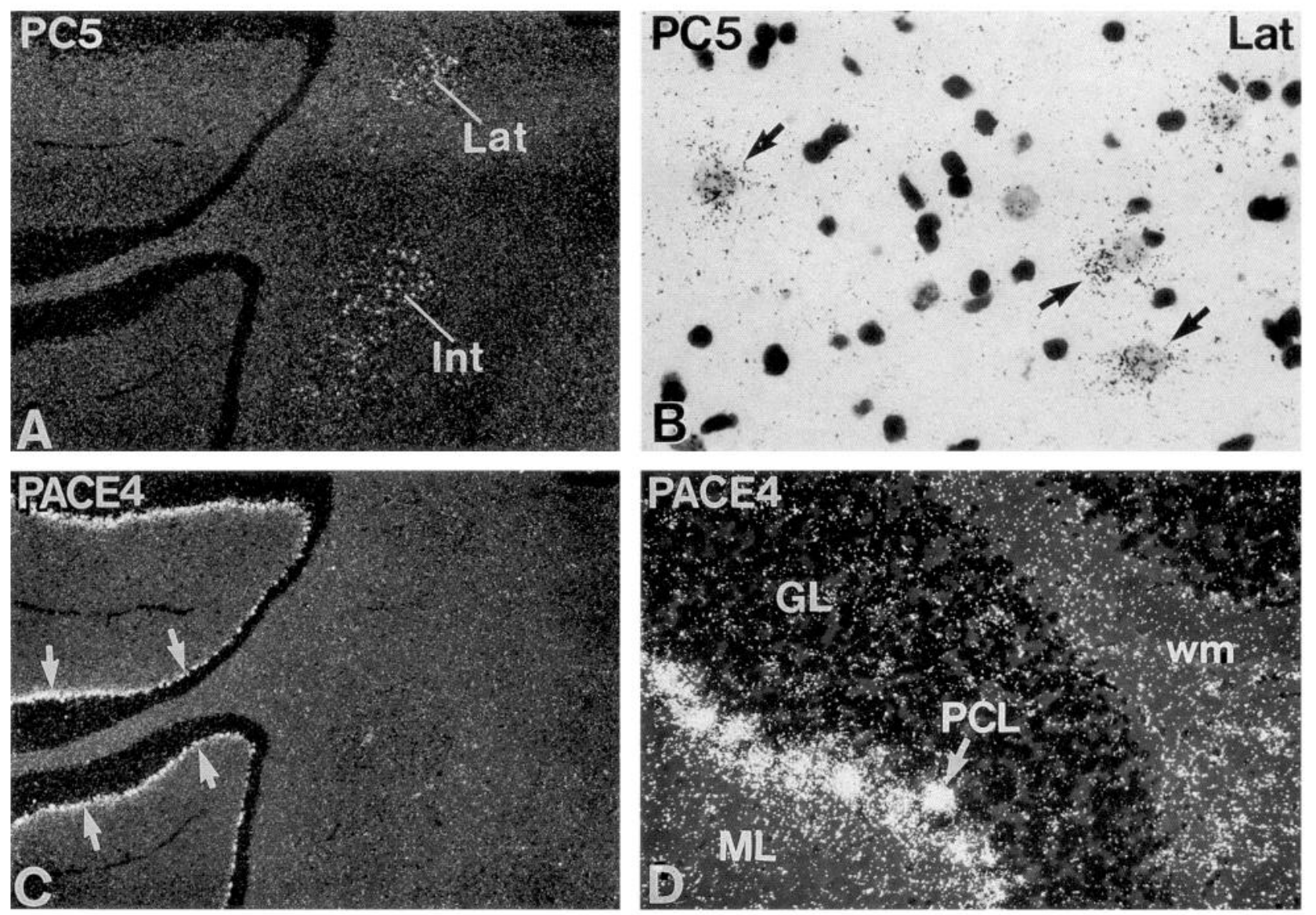

Figure 12. Gene expression of processing enzymes PC5 and PACE4 in the cerebellar cortex and deep nuclei. A, High levels of PC5 mRNA are observed in the lateral (Lat) and interpositus (Int) cerebellar nuclei. No labeling was seen in the cerebellar cortex. B, High power magnification of Lat cerebellar nucleus shows that the labeled cells are neurons. $C$, Intensive levels of PACE4 mRNA were observed in the Purkinje cell layer of the cerebellar cortex (arrows). D, Cerebellar cortex under high magnification shows the strongly labeled Purkinje cells $(P C L)$. Scattered cells in the granular layer $(G L)$ of the cerebellar cortex and in the white matter $(w m)$ of the cerebellar folia were weakly labeled. Magnification: $A$ and $C$, $20 \times ; B, 480 \times$; and $D, 150 \times$.

sopressin-containing magnocellular cells in the PVN are principally expressing PC1, while oxytocin containing magnocellular cells in the PVN are principally expressing PC5. While both cell types also express significant levels of PC2, colocalization studies will be necessary to establish the exact cellular distribution of PC1, PC2, and PC5 in the PVN with oxytocin and vasopressin. The role of each PC in these cells remains to be investigated and may be numerous since many neuropeptide precursors are localized in the PVN.

The available data (Schäfer et al., 1993) shows that PC1 mRNA is expressed at high level in the DG, PC2 mRNA levels are highest in the CA2 and CA3 subfields, while PC5 mRNA is highest in CA3 (Fig. 8). In contrast, furin expression is detected throughout the hippocampal formation. When considering potential substrates within the hippocampus, the neurotrophic factors are interesting candidates, since their precursors require cleavage at pairs of basic residues to generate biologically active growth factors (Maisonpierre et al., 1990) and studies using coexpression system have shown the ability of furin in the cleavage of mouse pro- $\beta$-NGF to mature NGF (Bresnahan et al., 1990). However, which prohormone convertase is involved in the processing of the neurotrophic factors in vivo is still unclear. The known neurotrophic factors include nerve growth factor (NGF), brain-derived neurotrophic factor (BDNF), hippocam- pus-derived neurotrophic factor (HDNF/NT-3), and NT-4. The gene expression of HDNF/NT-3 has been shown in CA1, CA2, and the DG (Ernfors et al., 1990). Since this represents an opposing distribution to that of PC5, it seems unlikely that PC5 could be responsible for the activation of HDNF/NT-3 in the hippocampus. Indeed, preliminary data in our laboratory support this notion and suggest that furin is the enzyme responsible for the processing HDNF/NT-3 (R. Murphy, S. Benjannet, and N. G. Seidah, unpublished observations). On the other hand, $\mathrm{PC1}$, $\mathrm{PC} 2$, or furin could potentially cleave HDNF/NT-3 in CA1, $\mathrm{CA} 2$, and the DG, while PC5 could be the processing enzyme of BDNF since it is highly expressed in the CA3 region (Ernfors et al., 1990). However, our data cannot resolve the issue of overlapping and/or redundant function(s) of the convertases for the neurotrophins, a subject that will have to await more detailed molecular and cellular analysis.

The question of overlapping and/or distinct actions of the convertases may be further exemplified when comparing the expression of the convertases with that of POMC. The expression of POMC is principally restricted to the pituitary, hypothalamic Arc, and to the NTS. It has been demonstrated that PC1 cleaves POMC mostly into ACTH and $\beta$-lipotrophin while $\mathrm{PC} 2$ produces principally $\alpha-\mathrm{MSH}$ and $\beta$-endorphin (Benjannet et al., 1991; Thomas et al., 1991). In the brain, the Arc and NTS express 

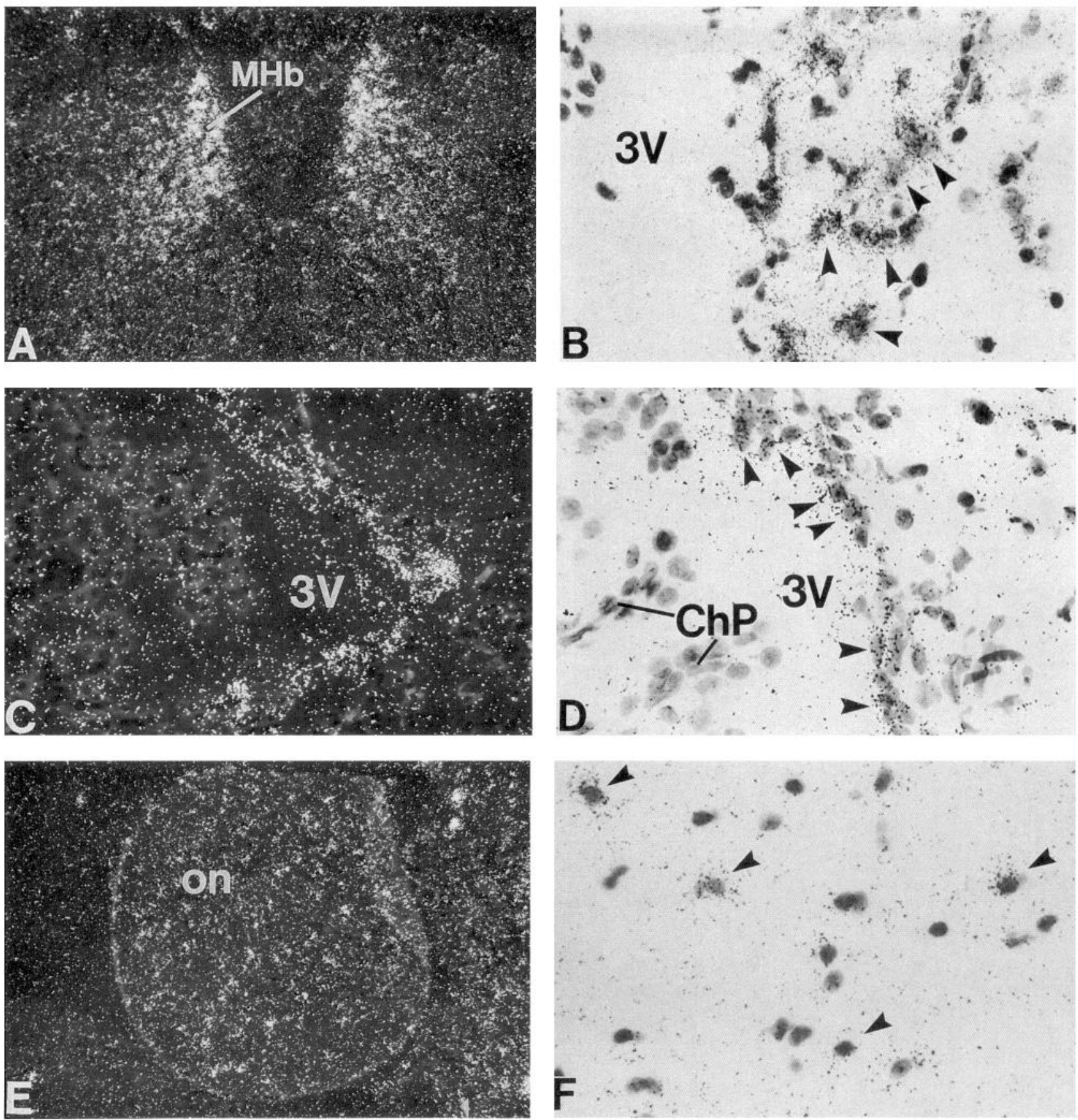

Figure 13. Distribution of PACE4 mRNA in $(A)$ the medial habenular nucleus $(M H b),(C)$ cells of third ventricle wall, and $(E)$ the optic nerve. In $A$, the upper portion of the MHb expressed intensive levels of PACE4 and in $B$ is shown a higher magnification bright-field image demonstrating that the majority of neurons in this region are positively labeled for PACE4 mRNA. In $C$, moderate levels of PACE4 mRNA were observed in cells of the wall of the third ventricle, and in $D$, a higher magnification shows the labeled cells. $E$, The cells in the optic nerve expressed moderate levels of PACE4 and in $F$, a higher magnification bright-field image reveals the glial cells in the optic nerve are PACE4 positive. Magnification: $A, 80 \times ; B$ and $D, 480 \times ; C 190 \times ; E, 90 \times ;$ and $F, 500 \times$.

both PC1 and PC2 (Schäfer et al., 1993) suggesting that POMC processing in these regions is also dependent on the same convertases. The present study adds a potentially new level of complexity in the understanding of POMC processing, since we observed medium to high levels of PACE4 and PC5 mRNA in the anterior lobe, Arc and NTS. Preliminary data demonstrated that although PACE4 is capable of cleaving POMC into $\beta$-LPH and $\beta$-endorphin, PC5 is not (S. Benjannet, and N. G. Seidah, unpublished observations). Taken together, these data suggest that more than one enzyme is capable of cleaving the same substrate at the same site. It remains to be established whether these interactions are actually occurring in a physiological context.

While the complexity of interactions between the convertases and their substrates is yet to be elucidated, our present findings highlight the potential actions of either PC5 or PACE4 in the processing of other neuropeptide precursors. The high level of PACE4 mRNA in the central amygdaloid nucleus, a region rich in neurotensin (Emson et al., 1982), is notable since in this area 
the other convertases are only expressed at very low levels (Schäfer et al., 1993). Another example is the cerebellar Purkinje cells, where PACE4 mRNA levels are very high and distinctive. The known peptides synthesized in these cells include pro-enkephalin (Osborne et al., 1992), and insulin-like growth factor-I (Andersson et al., 1988), which needs cleavage at a monobasic recognition site to create mature protein (Daughaday and Rotwein, 1989).

In conclusion, the data presented in this work and those obtained from previously published reports (Day et al., 1992, 1993; Schäfer et al., 1993) provide us with a wealth of information on the complex tissue localization of each processing enzyme. This starting point should stimulate further work leading to the elucidation of the tissue-specific role of each enzyme and to the definition of its potential substratcs. The integration of this information within the global context of brain development and function should allow us to better understand the diverse interactions that this family of processing enzymes can achieve.

\section{Appendix}

\section{Abbreviations}

$3 \mathrm{~V}$ third ventricle

ac anterior commissure

AO anterior olfactory nucleus

AL anterior lobe of the pituitary

Arc arcuate hypothalamic nucleus

BL basolateral amygdaloid nucleus

C cerebellum

CA1 field CA1 of Ammon's horn

CA2 field CA2 of Ammon's horn

CA3 field CA3 of Ammon's horn

$\mathrm{cc}$ corpus callosum

$\mathrm{Ce} \quad$ central amygdaloid nucleus

ChP choroid plexus

CM central medial thalamus nucleus

$\mathrm{CPu}$ caudate putamen

$\mathrm{Cx} \quad$ cortex

DG dentate gyrus

dp dorsal parvocellular division, paraventricular hypothalamic nucleus

DR dorsal raphé nucleus

DS deepest stratum of cerebral cortex layer VI

EPl external plexiform layer of the olfactory bulb

EnD endopiriform nucleus, dorsal

GL granular layer of the cerebellar cortex

Gl glomerular layer of the olfactory bulb

$\mathrm{Hi}$ hippocampal formation

IL intermediate lobe of the pituitary

IMD intermediodorsal thalamic nucleus

Int interpositus cerebellar nucleus

IP interpeduncular nucleus

Lat lateral cerebellar nucleus

Layer IV cerebral cortex, layer IV

Layer V cerebral cortex, layer V

Layer VI cerebral cortex, layer VI

lo lateral olfactory tract

MB mammillary body

MD mediodorsal thalamic nucleus

MDL mediodorsal thalamic nucleus, lateral part

MG medial geniculate nucleus

$\mathrm{MHb}$ medial habenular nucleus

$\mathrm{Mi}$ mitral cell layer of the olfactory bulb

ML molecular layer of the cerebellar cortex

mp medial parvocellular division, paraventricular hypothalamic

nucleus NL neural lobe of the pituitary

NIL neural and intermediate lobe of the pituitary

NTS nucleus tractus solitarius

$\mathrm{OB} \quad$ olfactory bulb

on optic nerve

ox optic chiasm

PC paracentral thalamic nucleus
PCL Purkinje cell layer of the cerebellar cortex

$\mathrm{Pe} \quad$ periventricular hypothalamic nucleus

pm posterior magnocellular division, paraventricular hypothalamic nucleus

PVA paraventricular thalamic nucleus, anterior

PVN paraventricular hypothalamic nucleus

PVP paraventricular thalamic nucleus

S subiculum

SON superoptic hypothalamus nucleus

VL ventrolateral thalamic nucleus

VPL ventral posterolateral thalamic nucleus

wm white matter

\section{References}

Alexander MJ, Miller MA, Dorsa DM, Bullock BP, Melloni RH Jr, Dobner PR, Leeman SE (1989) Distribution of neurotensin/neuromedin $\mathrm{N}$ mRNA in the rat forebrain: unexpected abundance in hip pocampus and subiculum. Proc Natl Acad Sci USA 86:5202-5206.

Andersson IK, Edwall D, Norstedt G, Rozell B, Skottner A, Hansson H-A (1988) Differing expression of insulin-like growth factor $I$ in the developing and in the adult rat cerebellum. Acta Physiol Scand 132:167-173.

Barr PJ, Mason OB, Landsberg KE, Wong PA, Kiefer MC, Brake AJ (1991) cDNA and gene structure for a human subtilisin-like protease with cleavage specificity for paired basic amino acid residues. DNA Cell Biol 10:319-328.

Batter DK, Vilijn MH, Kessler J (1991) Cultured astrocytes release proenkephalin. Brain Res 563:28-32.

Benjannet S, Rondeau N, Day R, Chrétien M, Seidah NG (1991) PC1 and $\mathrm{PC} 2$ are proprotein convertases capable of cleaving proopiomelanocortin at distinct pairs of basic residues. Proc Natl Acad Sci USA 88:3564-3568.

Bondy CA, Whitnall MH, Brady LS, Gainer H (1989) Coexisting peptides in hypothalamic neuroendocrine systems: some functional implications. Cell Mol Neurobiol 9:427-446.

Breslin MB, Lindberg I, Benjannet S, Mathis JP, Lazure C, Seidah NG (1993) Differential processing of proenkephalin by prohormone convertases 1 (3) and 2 and furin. J Biol Chem 268:27084-27093.

Bresnahan PA, Leduc R, Thomas L, Thorner J, Gibson HL, Black AJ, Barr PJ, Thomas G (1990) Human fur gene encodes a yeast kex2like endoprotease that cleaves pro- $\beta$-NGF in vivo. J Cell Biol 111: 2851-2859.

Burgunder JM, Young WS III (1989) Neurokinin B and substance P genes are co-expressed in a subset of neurons in the rat habenula. Neuropeptides 13:165-169.

Creemers JWM, Kormelink PJG, Roebroek AJM, Nakayama K, Van de Ven WJM (1993) Proprotein processing activity and cleavage site selectivity of the Kex2-like endoprotease PACE4. FEBS Lett 336: 65-69.

Daughaday WH, Rotwein P (1989) Insulin-like growth factor I and II. Peptide, messenger ribonucleic acid and gene structures, serum, and tissue concentrations. Endocr Rev 10:68-91.

Day R, Schäfer MK-H, Watson SJ, Chrétien M, Seidah NG (1992) Distribution and regulation of the prohormone convertases $\mathrm{PCl}$ and PC2 in the rat pituitary. Mol Endocrinol 6:485-497.

Day R, Schäfer MK-H, Watson SJ, Chrétien M, Seidah NG (1993) Region specific expression of furin mRNA in the rat brain. Neurosci Lett 149:27-30.

Emson PC, Goedert M, Horsfield P, Rioux F, St pierre S (1982) The regional distribution and chromatographic characterisation of neurotensin-like immunoreactivity in the rat central nervous system. J Neurochem 38:992-999.

Ernfors P, Wetmore C, Olson L. Persson H (1990) Identification of cells in rat brain and peripheral tissues expressing mRNA for members of the nerve growth factor family. Neuron 5:511-526.

Herrin DL, Schmidt GW (1988) Rapid, reversible staining of Northern blots prior to hybridization. Biotechniques 6:196 200 .

Kiefer MC, Tucker JE, Joh R, Landsberg KE, Saltman D, Barr PJ (1991) Identification of a second human subtilisin-like protease gene in the fes/fps region of chromosome 15. DNA Cell Biol 10:757-769.

König N, Valat J, Fulcrand J, Marty R (1977) The time of origin of Cajal-Retzius cells in the rat temporal cortex. An autoradiographic study. Neurosci Lett 4:21-26.

Lightman SL (1988) The neuroendocrine paraventricular hypothala- 
mus: receptors, signal transduction, mRNA and neurosecretion. J Exp Biol 139:31-49.

Low K, Allen RG, Melner MH (1992) Differential regulation of proenkephalin expression in astrocytes by cytokines. Endocrinology 131: 1908-1914.

Lusson J, Vieau D, Hamelin J, Day R, Chrétien M, Seidah NG (1993) cDNA structure of the mouse and rat subtilisin/kexin-like PC5: a candidate proprotein convertase expressed in endocrine and nonendocrine cells. Proc Natl Acad Sci USA 90:6691-6695.

Maisonpierre PC, Belluscio L, Squinto S, Ip NY, Furth ME, Lindsay RM, Yancopoulos GD (1990) Neurotropin-3: a neurotrophic factor related to NGF and BDNF. Science 247:1446-1451.

Nakagawa T, Hosaka M, Torii S, Watanabe T, Murakami K, Nakayama K (1993a) Identification and functional expression of a new member of the mammalian Kex2-like processing endoprotease family: its striking structural similarity to PACE4. J Biochem 113:132-135.

Nakagawa T, Hosaka M, Nakayama K (1993b) Identification of an isoform with an extremely large Cys-rich region of PC6, a kex2-like processing endoprotease. FEBS Lett 327:165-171.

Nakayama K, Kim WS, Torii S, Hosaka M, Nakagawa T, Ikumizu J, Baba T, Murukami K (1992) Identification of the fourth member of the mammalian endoprotease family homologous to the yeast Kex 2 protease. J Biol Chem 267:5897-5900.

Negro A, Tavella A, Facci L, Callegaro L, Skaper SD (1992) Interleukin-1 beta regulates proenkephalin gene expression in astrocytes cultured from rat cortex. Glia 6:206-212.

Osborne JG, Kindy MS, Hauser KF (1992) Expression of proenkephalin mRNA in developing cerebellar cortex of the rat: expression levels coincide with maturational gradients in Purkinje cells. Dev Brain Res 63:63-69.

Paxinos G (1985) The rat nervous system. Sydney: Academic.

Raedler E, Raedler A, Feldhaus S (1980) Dynamical aspects of neocortical histogenesis. Anat Embryol 158:253-269.

Rehemtulla A, Barr PJ, Rhodes CJ, Kaufman RJ (1993) PACE4 is a member of the mammalian propeptidase family that has overlapping but not identical substrate specificity to PACE. Biochemistry 32: $11586-11590$.

Roebroek AJM, Schalken JA, Leunissen JAM, Onnekink C, Gloemers HPJ, van de Ven WJM (1986) Evolutionary conserved close linkage of c-fes/fps proto-oncogene and genetic sequences encoding a receptor-like protein. EMBO J 5:2197-2202.

Salm A, Hatton G, Nilaver G (1982) Immunoreactive glial fibrillary acidic protein in pituicytes of the rat neurohypophysis. Brain Res 236: $471-476$.

Sawchenko PE, Swanson LW (1982) Immunohistochemical identification of neurons in the paraventricular nucleus of the hypothalamus that project to the medulla or to the spinal cord in the rat. J Comp Neurol 205:260-272.

Schäfer MK-H, Day R (1994) In situ hybridization techniques to study processing enzyme expression at the cellular level. Methods Neurosci 23:16-44.

Schäfer MK-H, Day R, Watson SJ, Akil H (1990a) Distribution of opioids in brain and peripheral tissues. In: Opioid peptides and receptors: biochemistry, physiology and pharmacology (Almeida OFX, Shippenberg TS, eds), pp 53-71. Berlin: Springer.

Schäfer MK-H, Day R, Ortega MR, Akil H, Watson SJ (1990b) Proen- kephalin messenger RNA is expressed both in the rat anterior and posterior pituitary. Neuroendocrinology 51:444-448.

Schäfer MK-H, Stoffers DA, Eipper BA, Watson SJ (1992) Expression of peptidylglycine $\alpha$-amidating monooxygenase (EC1.14.17.3) in the rat central nervous system. J Neurosci 12:222-234.

Schäfer MK-H, Day R, Cullinan WE, Chrétien M, Seidah NG, Watson SJ (1993) Gene expression of prohormone and proprotein convertases in the rat CNS: a comparative in situ hybridization analysis. J Neurosci 13:1258-1279.

Seidah NG, ed (1991) Enzyme: pro-protein and pro-hormone convertases, Vol 45, pp 237-323. Basel: Karger.

Seidah NG, Chrétien M (1992) Pro-protein and pro-hormone convertases of the subtilisin family. Recent developments and future perspectives. Trends Endocrinol Metab 3:133-140.

Seidah NG, Gaspar L, Mion P, Marcinkiewicz M Mbikay M, Chrétien M (1990) cDNA sequence of two distinct pituitary proteins homologous to Kex2 and Furin gene products: tissue-specific mRNAs encoding candidates for prohormone processing proteinases. DNA Cell Biol 9:415-424.

Seidah NG, Marcinkiewicz M, Benjannet S, Gaspar L, Beaubien G, Mattei MG, Lazure C, Mbikay M. Chrétien M (1991) Cloning and primary sequence of a mouse candidate prohormone convertase PC1 homologous to PC2, furin, and kex 2: distinct chromosomal localization and messenger RNA distribution in brain and pituitary compared to PC2. Mol Endocrinol 5:111-122.

Seidah NG, Day R, Hamelin J, Gaspar A, Collard MW, Chrétien M (1992) Testicular expression of PC4 in the rat: molecular diversity of a novel germ cell-specific KEX2/subtilisin-like pro-protein convertase. Mol Endocrinol 6:1559-1569.

Scidah NG, Day R, Marcinkicwicz M, Chréticn M (1993) Mammalian paired basic amino acid convertases of prohormones and proproteins. Ann NY Acad Sci 680:135-146.

Smeekens SP, Steiner DF (1990) Identification of a human insulinoma cDNA encoding a novel mammalian protein structurally related to the yeast dibasic processing protease Kex2. J Biol Chem 265:29973000 .

Smeekens SP, Avruch AS, LaMendola J, Chan SJ, Steiner DF (1991) Identification of a cDNA encoding a second putative prohormone convertase related to PC2 in AtT-20 cells and islets of Langerhans. Proc Natl Acad Sci USA 88:340-344.

Thomas L, Leduc R, Thorne BA, Smeekens SP, Steiner DF, Thomas G (1991) Kex2-like endoproteases PC1 and PC3 accurately cleave a model prohormone in mammalian cells: evidence for a common core of neuroendocrine processing enzymes. Proc Natl Acad Sci USA 88: $5297-5230$.

Torres-Aleman I, Pons S, Garcia-Segura IM (1991) Climbing fiber deafferentation reduces insulin-like growth factor I (IGF-I) content in cerebellum. Brain Res 564:348-351.

Tsuji A, Higashine K, Hine C, Mori K, Tami Y, Nagamune H, Matsuda $Y$ (1994) Identification of the novel cDNAs encoding human kexinlike protease, PACE4 isoforms. Biochem Biophys Res Commun 200: 943-950.

Van de Ven WJM, Voorberg J, Fontijn R, Pannckock H, van den Ouweland AMW, van Duijnhoven HLP, Roebroek AJM, Siezen RJ (1990) Furin is a subtilisin-like proprotein processing enzyme in higher eukaryotes. Mol Biol Rep 14:265-275.

Wasley LC, Rehemtulla A, Bristol JA, Kaufman J (1993) PACE/furin can process the vitamin K-dependent pro-factor IX precursor within the secretory pathway. J Biol Chem 268:8458-8465. 